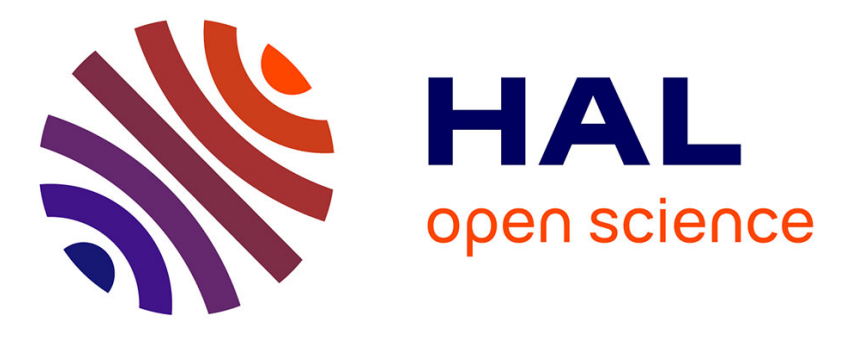

\title{
EvoluSon: Walking through an Interactive History of Music
}

Ronan Gaugne, Florian Nouviale, Octavia Rioual, Arnaud Chirat, Kevin Gohon, Vincent Goupil, Martin Toutirais, Bruno Bossis, Valérie Gouranton

\section{- To cite this version:}

Ronan Gaugne, Florian Nouviale, Octavia Rioual, Arnaud Chirat, Kevin Gohon, et al.. EvoluSon: Walking through an Interactive History of Music. Presence: Teleoperators and Virtual Environments, 2018, Special Issue: Virtual and Augmented Reality in Culture and Heritage, 26 (3), pp.281-296. 10.1162/pres_a_00298. hal-01661727

\section{HAL Id: hal-01661727 \\ https://hal.inria.fr/hal-01661727}

Submitted on 12 Dec 2017

HAL is a multi-disciplinary open access archive for the deposit and dissemination of scientific research documents, whether they are published or not. The documents may come from teaching and research institutions in France or abroad, or from public or private research centers.
L'archive ouverte pluridisciplinaire HAL, est destinée au dépôt et à la diffusion de documents scientifiques de niveau recherche, publiés ou non, émanant des établissements d'enseignement et de recherche français ou étrangers, des laboratoires publics ou privés. 


\title{
EvoluSon: Walking through an Interactive History of Music
}

\author{
Ronan Gaugne ${ }^{1}$, Florian Nouviale ${ }^{2}$, Octavia Rioual ${ }^{3}$, Arnaud Chirat ${ }^{3}$, Kevin Gohon ${ }^{3}$, Vincent Goupil ${ }^{4}$, \\ Martin Toutirais ${ }^{4}$, Bruno Bossis ${ }^{3}$, Valérie Gouranton ${ }^{2}$ \\ ${ }^{1}$ Université de Rennes 1/IRISA/Inria, France, \\ ${ }^{2}$ INSA Rennes/IRISA/Inria, France, \\ ${ }^{3}$ Université de Rennes 2, France, \\ ${ }^{4}$ ESIR, France
}

\begin{abstract}
The EvoluSon project proposes an immersive experience where the spectator explores an interactive visual and musical representation of the main periods of the history of Western music. The musical content is constituted of original musical compositions based on the theme of Bach's Art of Fugue to illustrate the eight main musical eras from Antiquity to the contemporary epoch.

The EvoluSon project contributes at the same time to the usage of VR for intangible culture representation and to interactive digital art that puts the user at the centre of the experience. The EvoluSon project focuses on music through a presentation of the history of Western music, and uses virtual reality to valorise the different pieces through the ages. The user is immersed in a coherent visual and sound environment and can interact with both modalities.

This project is the result of collaboration between a computer science research laboratory and a research laboratory on art and music. It was first presented to a public event on science and music organised by the computer science research laboratory.
\end{abstract}

\section{Introduction}

At the crossroad of art, culture and science, the EvoluSon project proposes an immersive experience where the spectator explores an interactive visual and musical representation of the main periods of the history of Western music. It is a result of collaboration between the Virtual Reality (VR) department of the computer science research laboratory IRISA and the research team "Arts : pratiques et poétiques" of University of Rennes 2 on music and arts. The project was initially designed for a public event dedicated to science and music.

The result of the project is a VR application on the history of musical composition, which is itself constituted of original musical compositions that illustrate different musical eras. It thus can be considered at two different levels:

1/ EvoluSon constitutes a pedagogical support for an illustration of the historical developments of Western music.

2/ EvoluSon is itself an artistic realisation associating an interactive graphical environment to original musical pieces.

In that sense, the EvoluSon project contributes at the same time to the usage of VR for intangible culture representation and to interactive digital art that puts the user at the center of the experience. The EvoluSon project proposes the design and implementation of an interactive exhibit for a public event that proposes a time travel in the history of Western music. Thanks to a coherent design of the visual content, the musical compositions, and the interactions, with respect to the different eras of the history of Western music, the EvoluSon project contributes also to illustrate the interest of VR for education in culture and heritage.

\section{Context}


Virtual Reality is already recognised as a powerful media for Culture, especially in museums, as it provides a user experience that induces a deep participation (Osberg, 1995). The sense of "being there" experienced by the user in VR reinforces his/her enjoyment (Sylaiou, Mania, Karoulis \& White, 2010) resulting in a positive experience that is enriching, even the more so as it provides natural interactions that favour the involvement of the user. According to Champion (2011), VR as a media for Culture "lends itself to both social and cultural learning as vicariously explored through doing rather than imaginatively reconstructed (as in book reading) or experientially followed (as in linear media like films)." This observation echoes to the notion of "cone of experience" presented by Dale (1969) who argues that we assimilate only $10 \%$ of what we read but $90 \%$ of what we do.

Nevertheless, the activity is strongly related to the interactions offered during the virtual experience. As pointed by Carrozzino \& Bergamasco (2010), natural interaction and high immersion provide an experience easier to access for people with no experience with computers, but in this case, interaction metaphors must be carefully designed. Champion (2015) particularly emphasizes the importance of the richness of the cultural interaction that remains currently poorly developed in the domain of Cultural Heritage.

Another modality that dramatically increases immersion is the sound. Numerous works demonstrate the importance of this modality in immersive virtual reality systems to enhance user experience (Nordahl \& Nilsson, 2014). Pressing (1997) highlights the importance of both sound and music in virtual environment, and the relations between sonification, algorithmic composition, virtual musical instruments and virtual sound sources. He advocates for music-theoretic research for virtual environments. In (Bishop, 2012), Bishop also illustrates the importance of the sound to enhance learning in multimedia and presents different strategies for the sound design in order to increase the level of engagement of a learner during a lesson. This is particularly critical when the learning content is related to music like in (Jørgensen, Knudsen, Wilmot, Lund, Serafin \& Purwins, 2015).

Sounds and music can also be combined into interactive virtual reality environments to produce a recreational or artistic experience in public exhibitions (Nakra, Ivanov, Smaragdis \& Ault, 2009; Simon, Nouviale, Gaugne \& Gouranton, 2014). In these examples, the visitor interacts with the virtual environment to influence or produce a musical and sound environment. This approach is also used to propose new concepts of musical instruments called "Virtual Reality Musical Instruments" (VRMIs) like in (Leonard et al. 2013) and (Valbom \& Marcos, 2007). Conversely, virtual reality environments can be used to enhance the access to the music for the pubic as in (Berthaut, Marshall, Subramanian, \& Hachet, 2013) and (Berthaut, Zappi, \& Mazzanti, 2014). In all cases, Serafin et al. (2015) and Bowman, Kruijff, LaViola, \& Poupyrev, (2004) both push the use of both natural and "magical" interactions and musical instruments in VRMIs in order to allow the player to overcome the real-world limitations.

In the domain of Cultural Heritage, the importance of sound and music is identified, especially for intangible heritage such as ceremonies (Papagiannakis, Foni \& Magnenat-Thalmann, 2003), civilisation (Froschauer et al. 2010), and of course music (Castro et al., 2006). It also has been proved that the acoustic properties of the places for whom music is designed "not only shape the sounds that they contain, but also influence musical styles as composers try to optimize their music for the space” (Blesser \& Salter, 2009). Nevertheless, sounds and music are seldom present in Virtual Heritage for Cultural Heritage projects, and still less as a central element of reconstitutions.

The EvoluSon project focuses on music through a presentation of the history of music, and uses virtual reality to valorise the different pieces through the ages. The user is immersed in a coherent visual and sound environment and can interact with both modalities. We now detail the content of EvoluSon, its conceptual and technical implementation. 


\section{Method}

As a combination of music, images and interactions, EvoluSon has been designed in a collaborative process mixing music composers, musicians, historians of music and computer engineers and scientists. All the aspects of graphic design, music composition and virtual reality design and implementation have been processed together, era per era. The graphical environments and music compositions corresponding to the different eras were designed in an overall concern of global coherency.

\subsection{Graphical environment}

The graphical universe of EvoluSon is a succession of eight rooms or landscapes, each one representing one of the eight eras of music presented in the project. Each era is characterized by strong visual clues, borrowed from different domains of art such as architecture, painting, cinema or video games. The point is not to provide an exact reconstitution of each era, but to propose a graphical environment easily identifiable by the user. The eight eras of music are Antiquity, Middle Age, Renaissance, Baroque era, Classic era, Romantic era, Modern era, and Contemporary era.

\subsection{Musical representation}

As the project aims to represent the overall evolution of the musical language in Western music history, it has been decided to develop eight musical contexts related to the main historical eras of this culture. However, these musical contexts visually depicted as different rooms are not based on the presentation of existing works written at the selected historical periods: for didactic purposes, it seemed more relevant to work on original short compositions based on the same melodic cell exposed according to the main norms of each style. This process not only enlightens the evolution of the musical aesthetics, it also allows a certain continuity between the various rooms and provides coherence to the realisation. The melodic cell that has been chosen in this perspective is the main theme - which is called a "subject" - of Bach's Art of Fugue (Fig. 1) due to the neutrality of its melodic shape as well as its symbolic significance in the history of music.

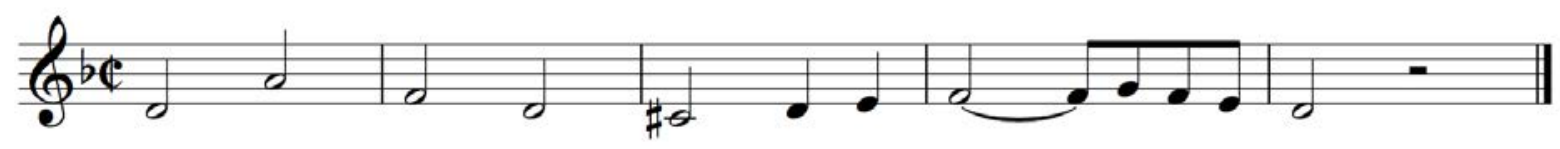

Figure 1: The subject of Bach's Art of Fugue

\subsection{Interactive simulation}

One important aspect of the visit in EvoluSon is the possibility for the visitor to interact with both graphical and sound environments. During his/her visit, the user holds a tracked wand with a joystick to navigate and a trigger to interact. A wooden stick is displayed to extend the physical wand in the digital world and to represent a pointer for the user. This representation of the interaction evokes at the same time a conductor's baton and a magician's wand. The interactions proposed to the visitors, in addition to the navigation in the EvoluSon universe, can be separated in two types:

1. Interaction with information: in each era representation, two icons are floating, one with a question mark for the description of the interactions proposed to the visitor, and one with a music note for 
the description of the music composition. When the visitor points one of these icons, it becomes highlighted, and when the user clicks on the button, an information board is displayed, with 2D graphical and textual explanations. (Fig. 2)

2. Interaction with the environment: for each period, different interactions are proposed to the user, with a progression in complexity. The interactions are also more and more related to the music when advancing in time.

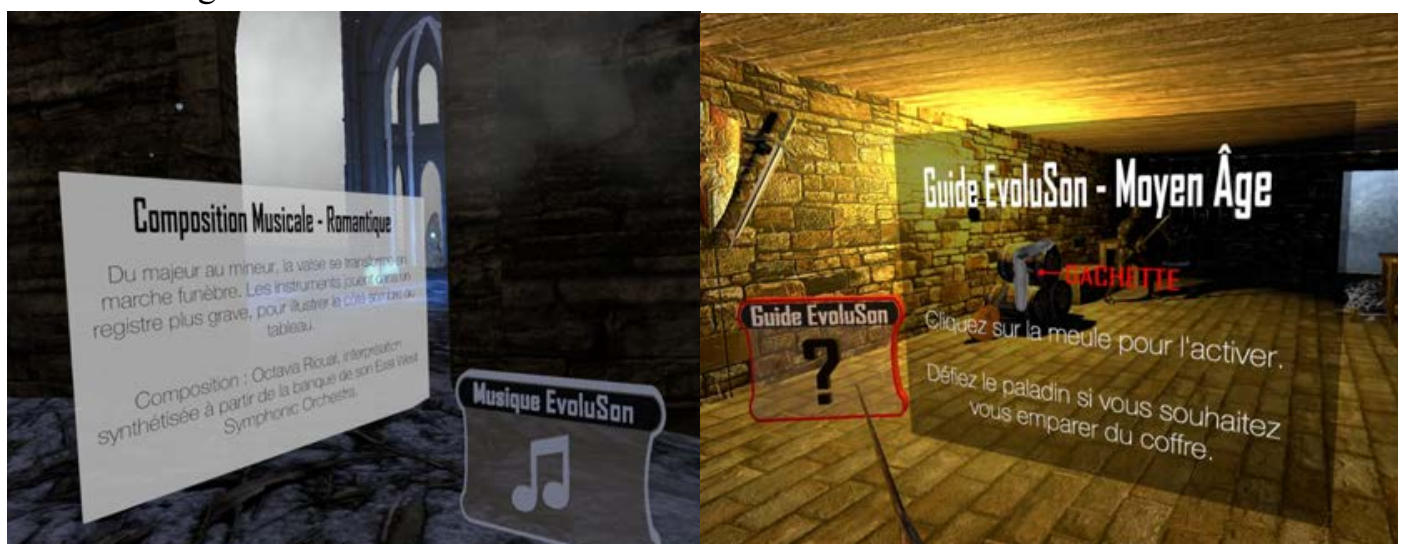

Figure 2. Information display. Left: Music description. Right: Interaction description

\subsection{Public representation and evaluation}

The EvoluSon project was publicly presented during the Day of Science and Music, an annual event organised by the Computer Science Research Institute IRISA, in Rennes, France. During this event, the EvoluSon project was presented to the public in a large Cave-like facility. At the end of the visit, a questionnaire was proposed to the visitors in order to get feedback on their experience.

\section{Description of the work}

The graphical and musical environment of EvoluSon has been designed to accompany the visitor in his/her interactive journey through eight eras of musical composition, from Antiquity to the contemporary epoch. Interactions were designed to involve the visitor during his/her trip and create a relationship with the musical pieces.

\subsection{Graphical environment}

The visitor starts in an external garden representing Antiquity, as illustrated in Fig. 3. The graphical representation of the Antique era relies on architectural clues, with the Greek temple Parthenon, the Roman Coliseum, Greek columns and vases in the garden, and one Greek sculpture. A shining blue door, in the Parthenon indicates the way to the next era. 


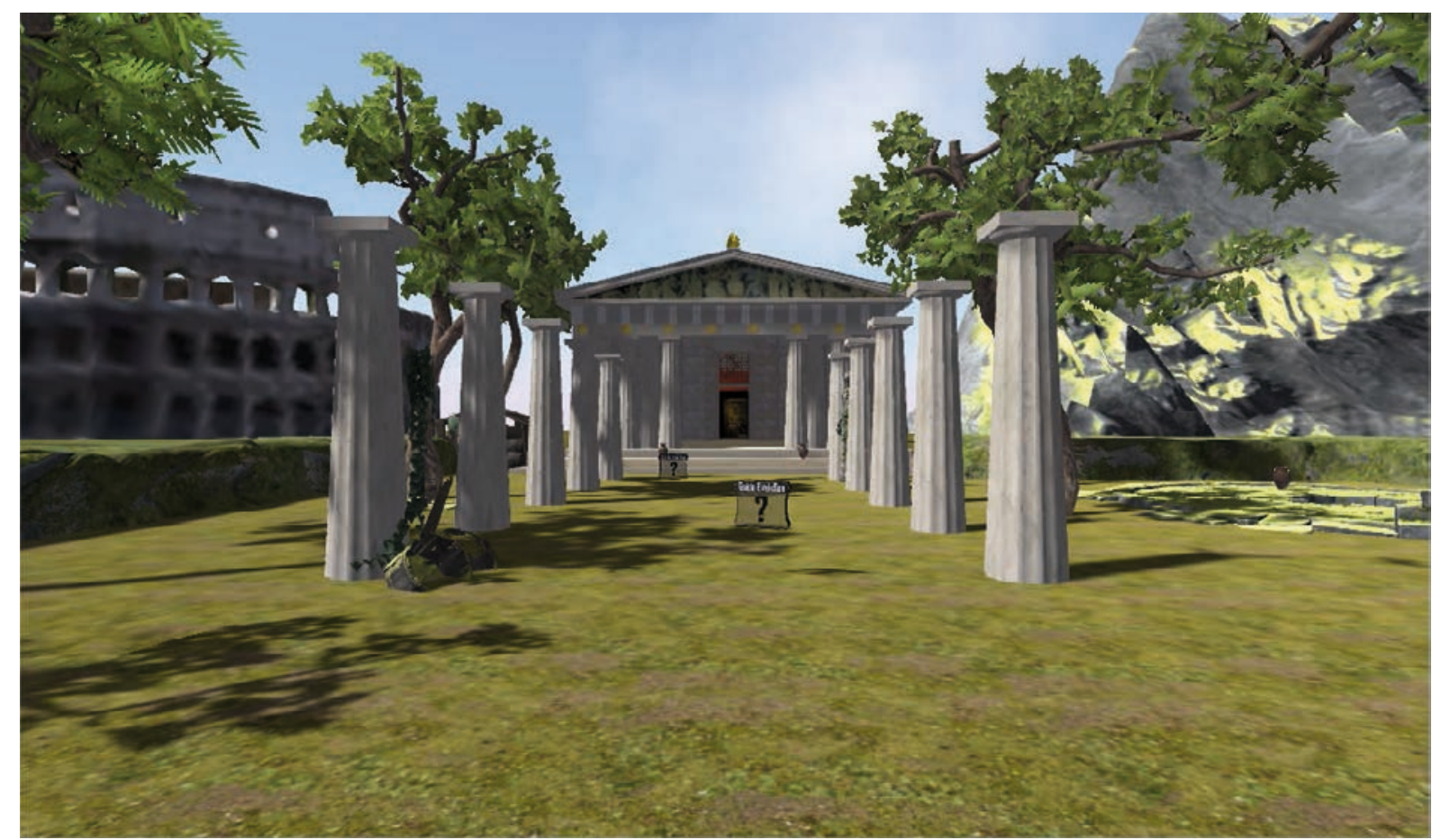

Figure 3. The Antique garden

A forge, as illustrated in Fig. 4, represents the Medieval era. The different elements of the room are inspired by video games of medieval fantasy, with a blacksmith dwarf, and a warlike paladin defending a treasure. A hammer magically strikes a piece of iron close to the hearth of the forge. Different swords are displayed in the room, to fight the paladin, including a Minecraft ${ }^{1}$-designed sword. The music is visually present in the room with an animated lute player, and musical instruments spread around.

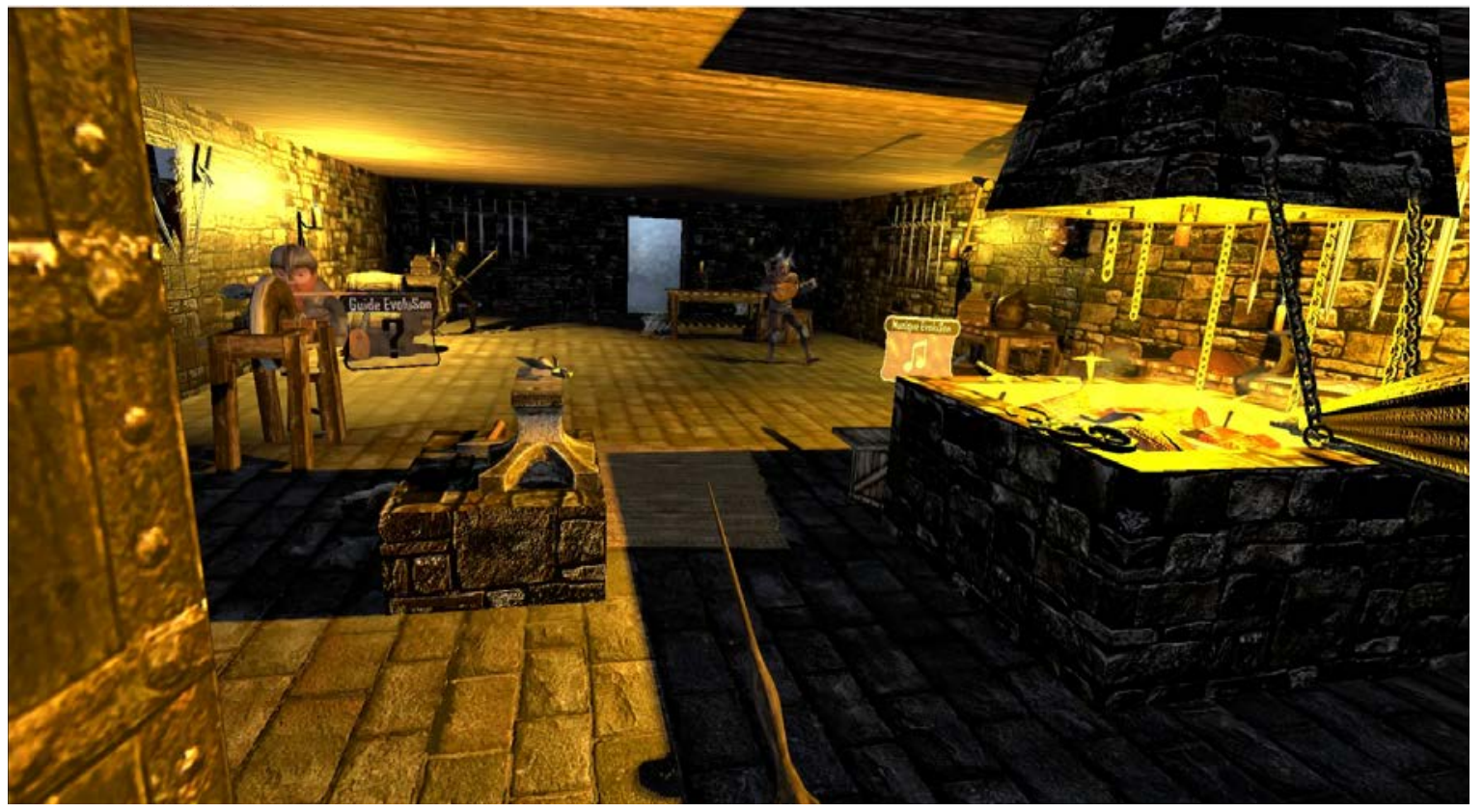

Figure 4. The Medieval blacksmith

\footnotetext{
${ }^{1} \mathrm{http}: / /$ minecraft.net
} 
The Renaissance era is represented by a large living room, with typical ornaments such as a Renaissance chandelier, and a painted ceiling. The dimensions of the room can change during the visit (Fig. 5).

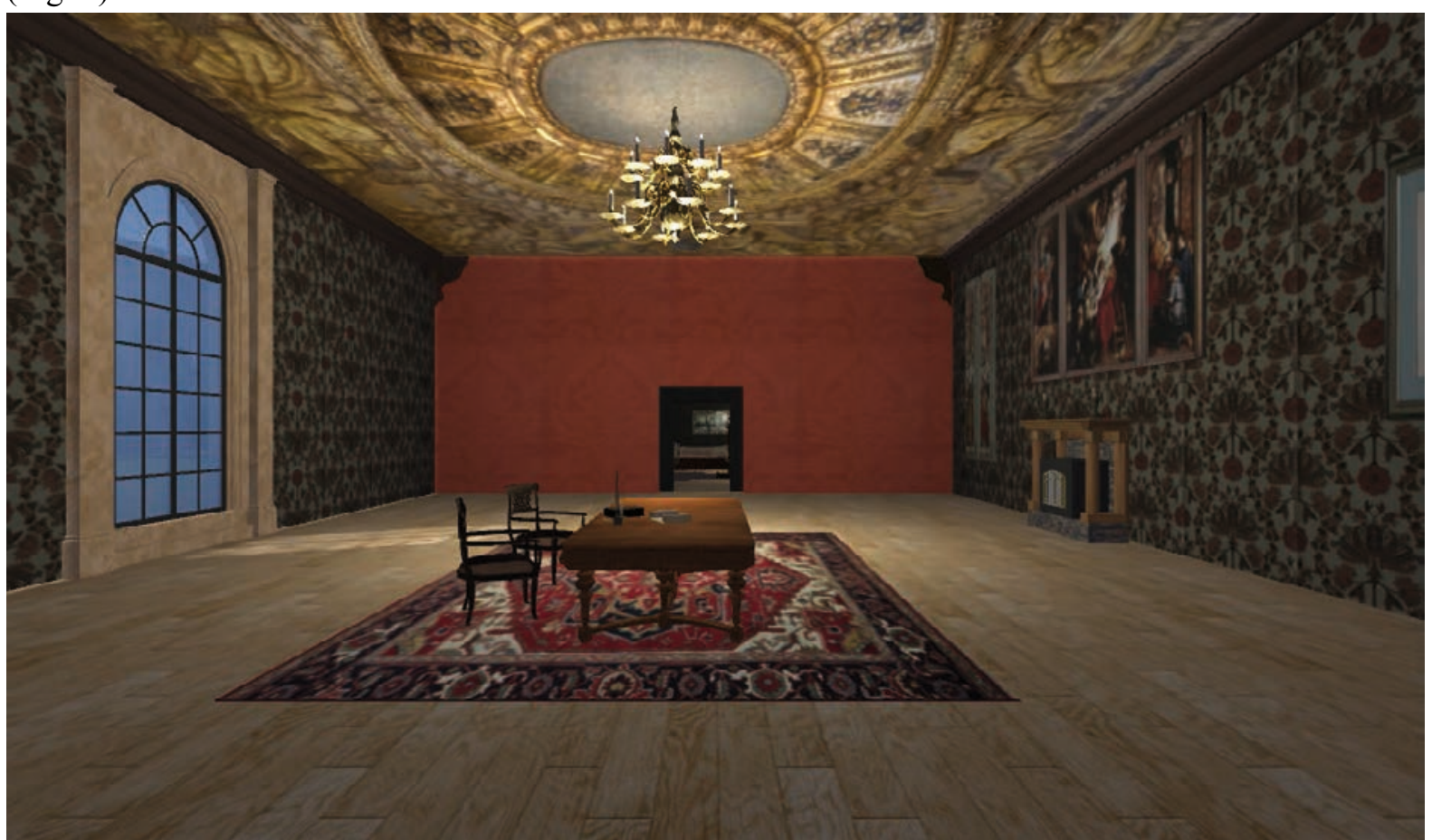

Figure 5. The Renaissance hall

The Baroque room is a chamber (Fig. 6) with seven musical instruments distributed all over the room, the four instruments of a string quartet, two oboes and one bassoon, referring to chamber music. The painting "The anatomy lessons of Dr. Nicolaes Tulp" by Rembrandt is displayed on the back wall of the room.

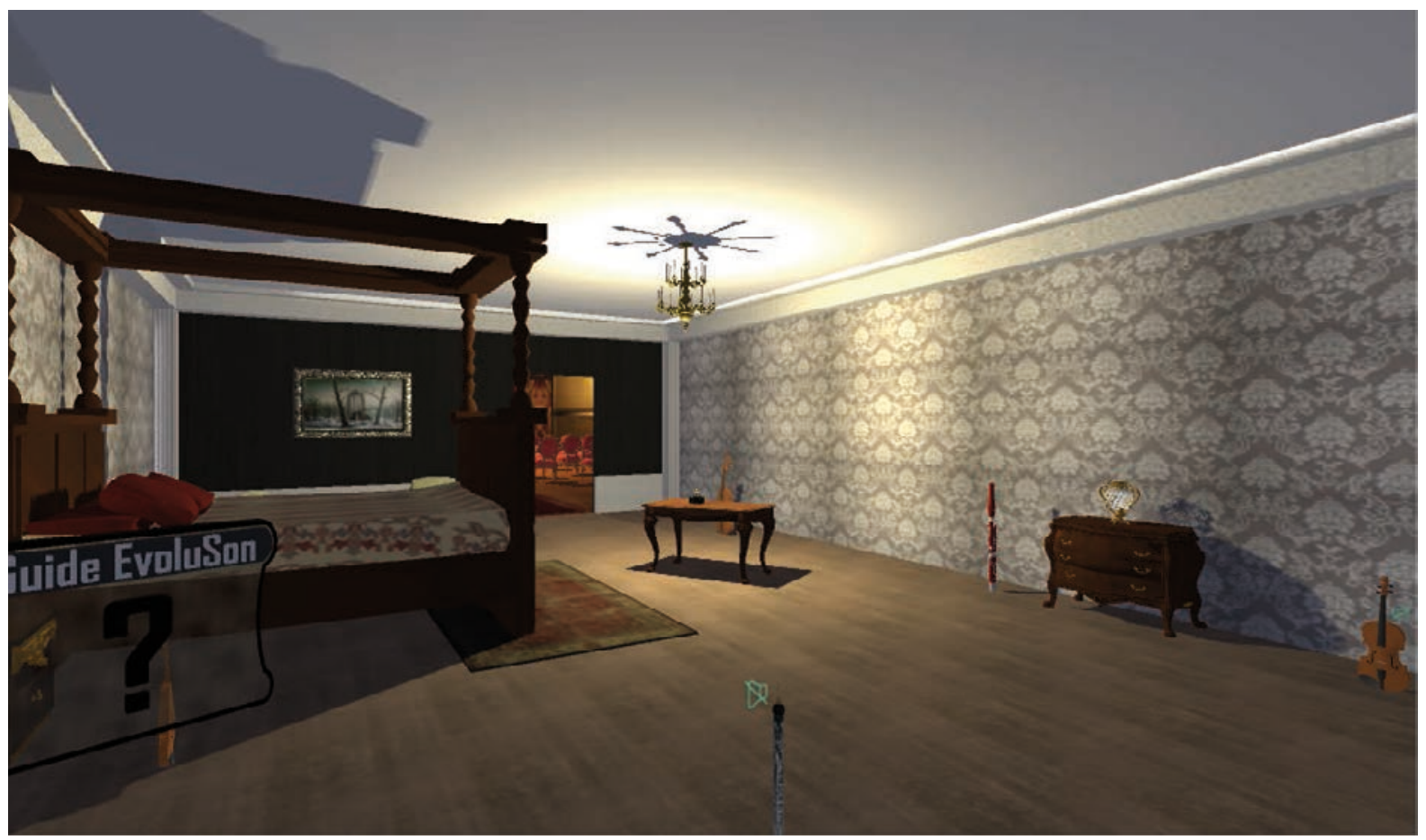

Figure 6. The Baroque chamber 
The Classical era is presented in a concert hall, with a piano on the stage (Fig. 7), as piano concerts were very popular in this period.

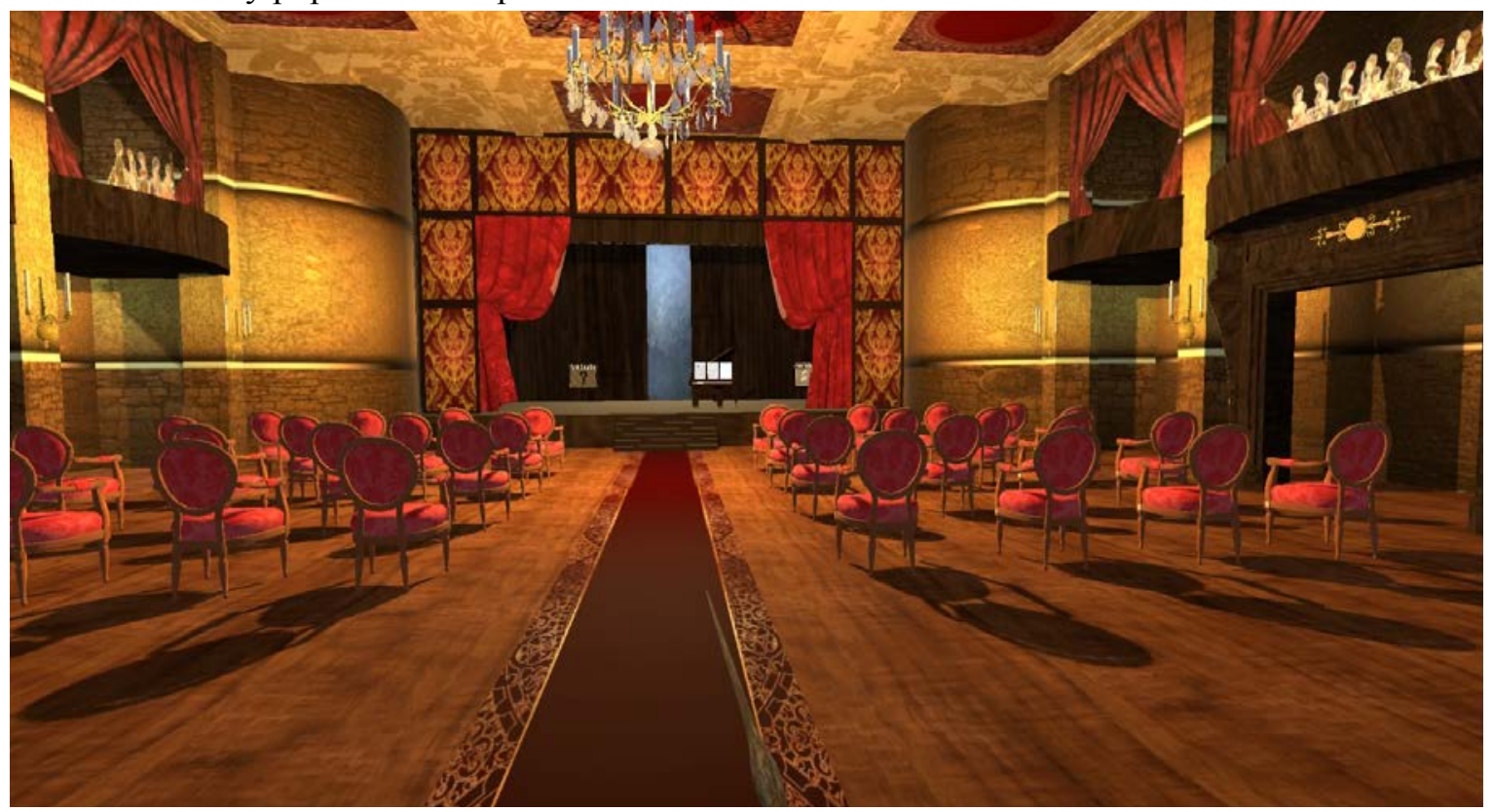

Figure 7. The Classical theatre

For the Romantic era, the visitor enters in a large ballroom (Fig. 8), inspired by the ballroom of the Walt Disney animated musical romantic fantasy "Beauty and the Beast" (1991), with flying dancers inspired by the Terry Gilliam movie "The adventures of Baron Munchausen" (1988). In a hidden room (Fig. 9), the Romantic painting "Monastery Graveyard in the Snow" by Caspar David Friedrich is presented to the visitor and gives access to its 3D reconstitution (Fig. 10).

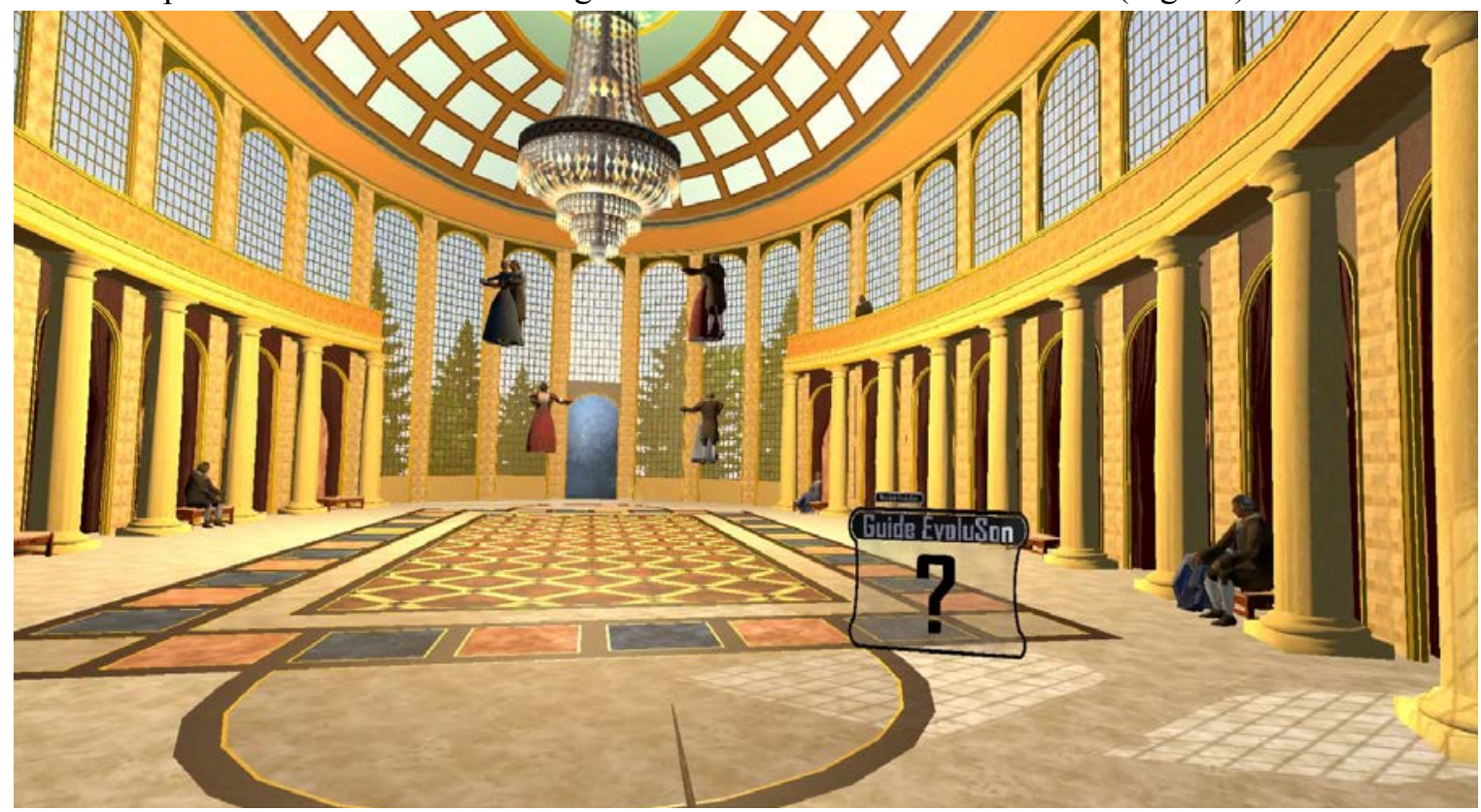

Figure 8. The Romantic ballroom 


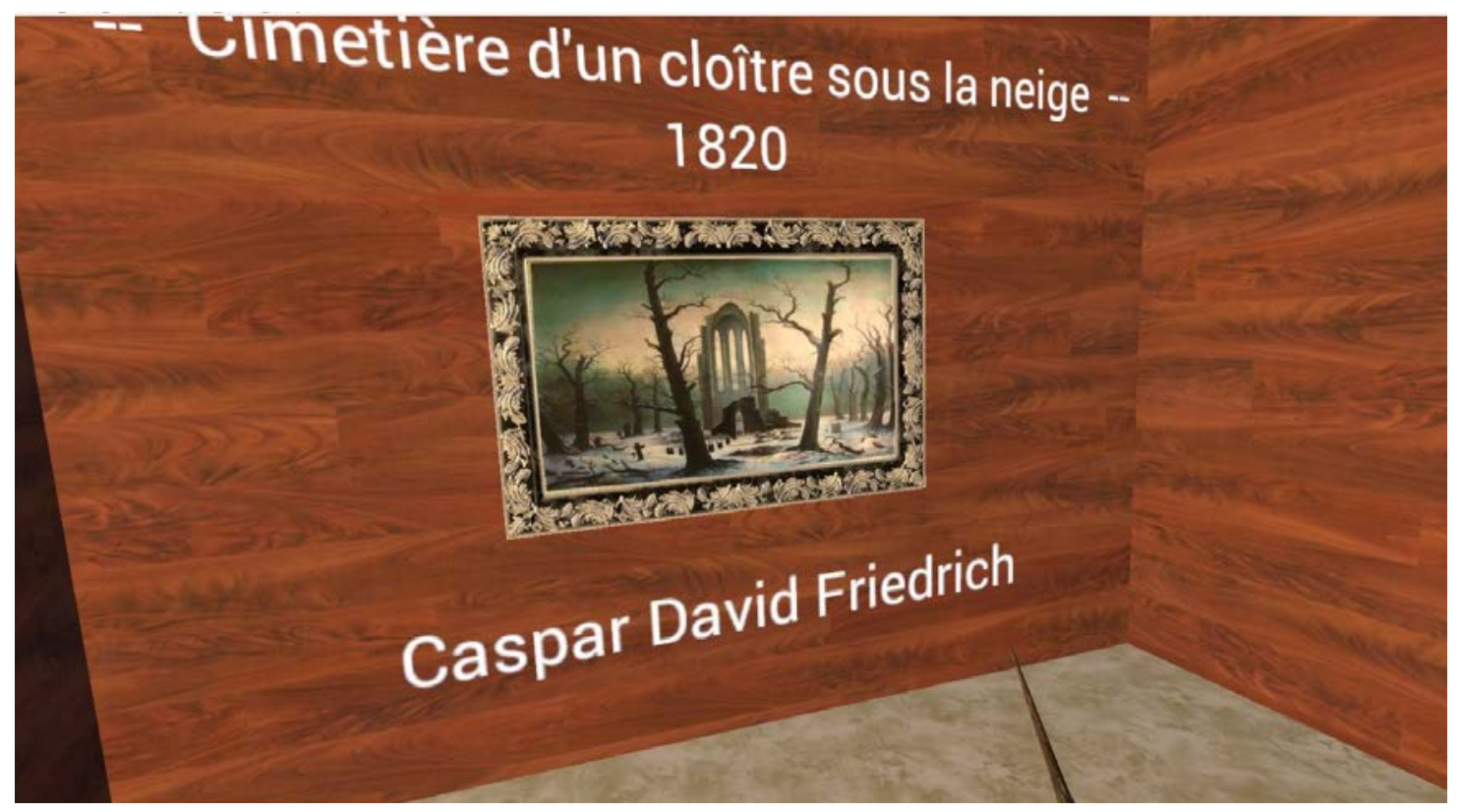

Figure 9. The Friedrich painting inside the secret room

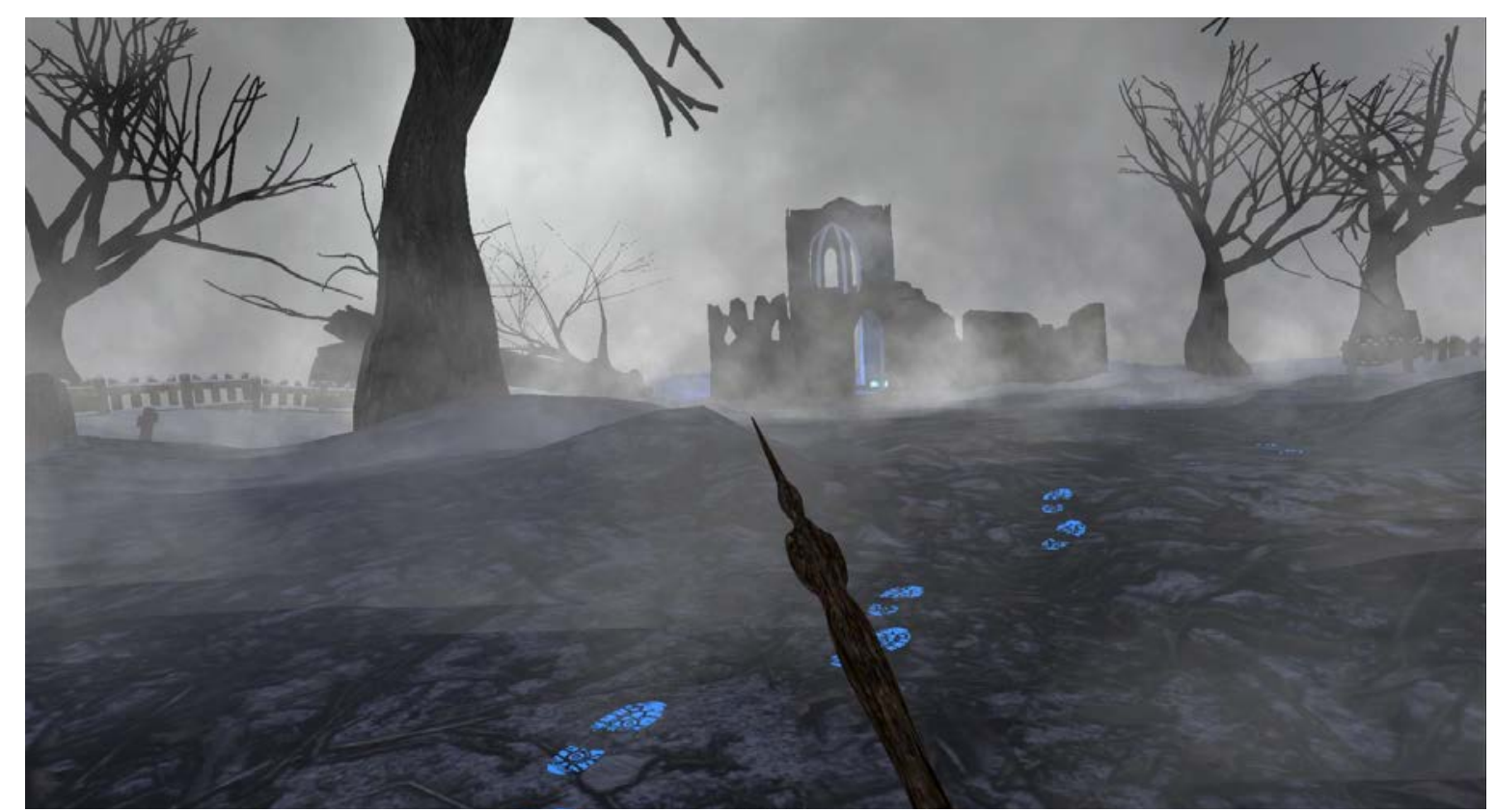

Figure 10. Inside the Friedrich painting

The Modern era representation is inspired by the Charlie Chaplin movie "Modern times" with large gears turning according to the music play (Fig. 11). The Modern room is an industry factory typical of the beginning of 20th century, with two electric machines in the centre with levers to control the music (Fig. 12). In the right part of the room, a conveyor belt carries industrial manufactured items. 


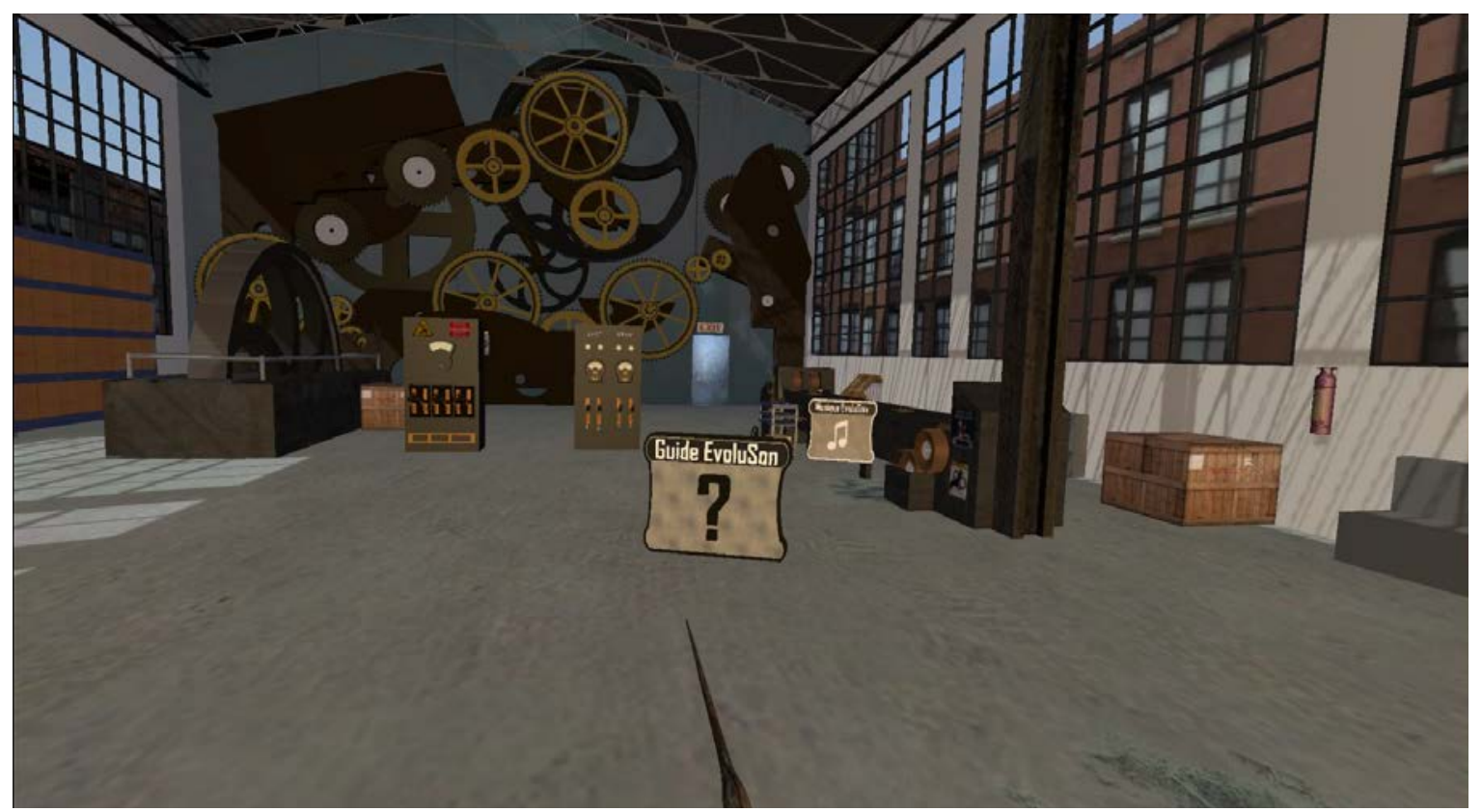

Figure 11. The Modern factory

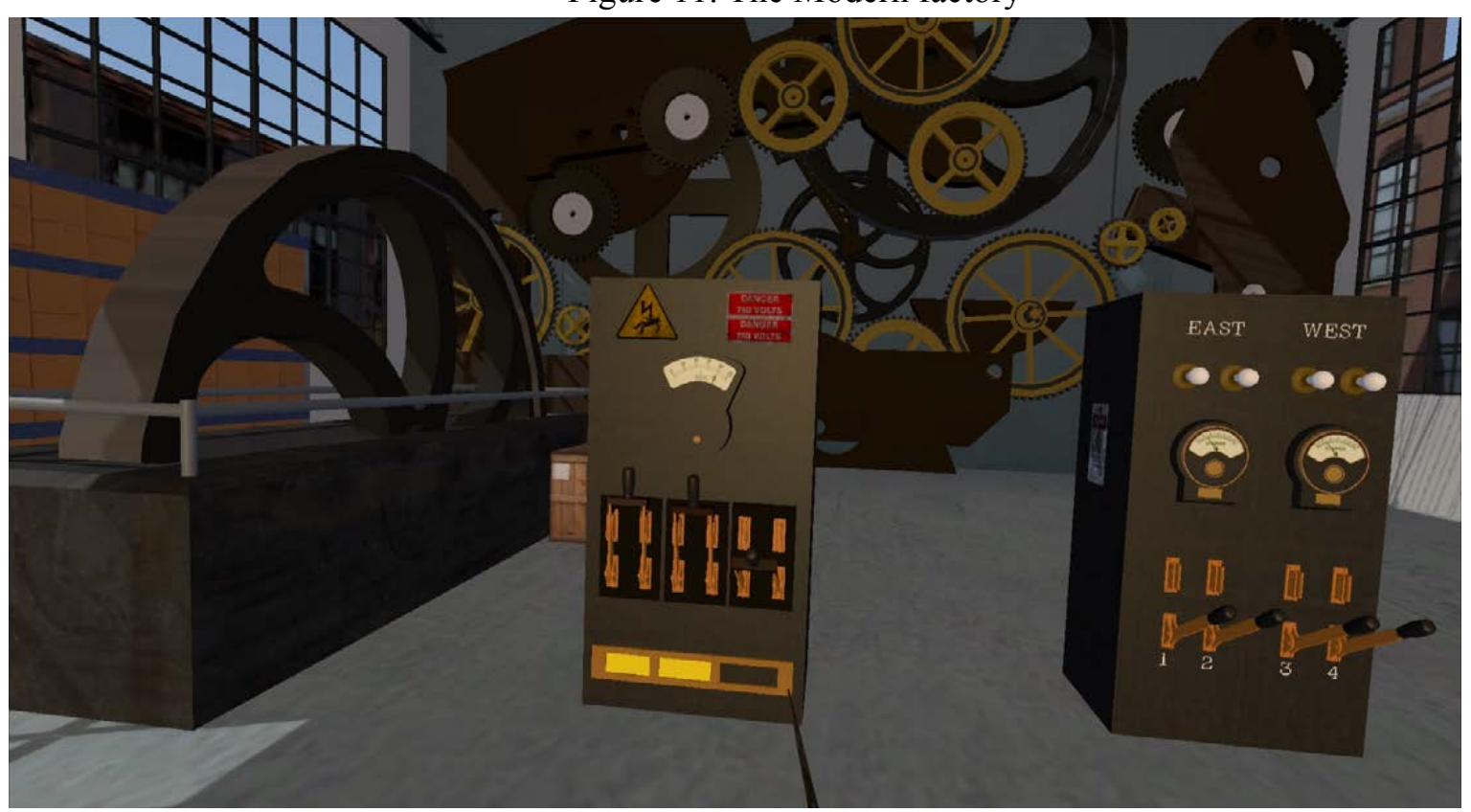

Figure 12. The electric machines to control music

The last era, the Contemporary period, is presented in a recording studio. The visitor enters in the control room (Fig. 13) and can access the live room equipped with a Moog console (Fig. 14), an emblematic synthesizer in the field of electronic music. 


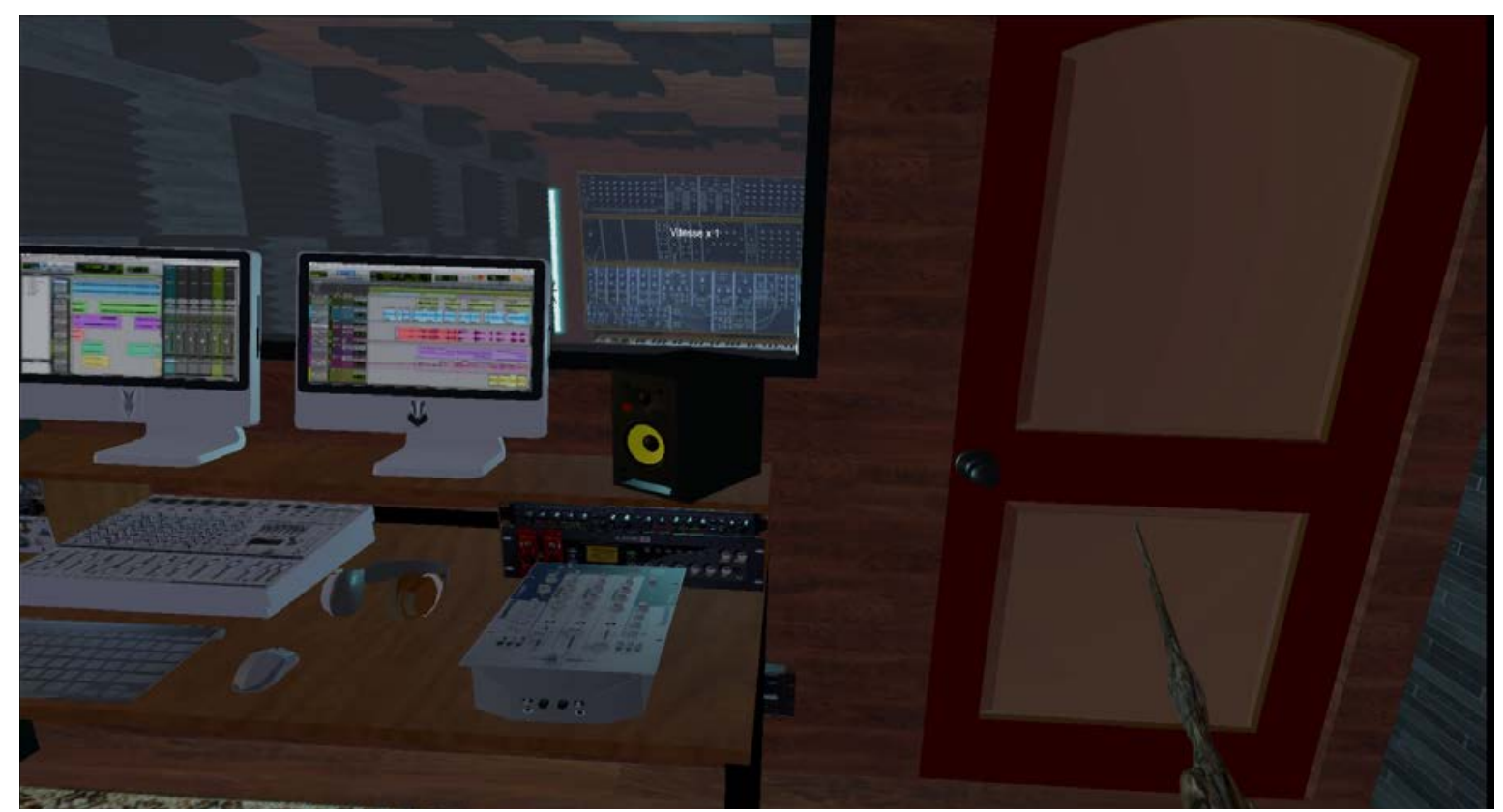

Figure 13. The Contemporary recording studio

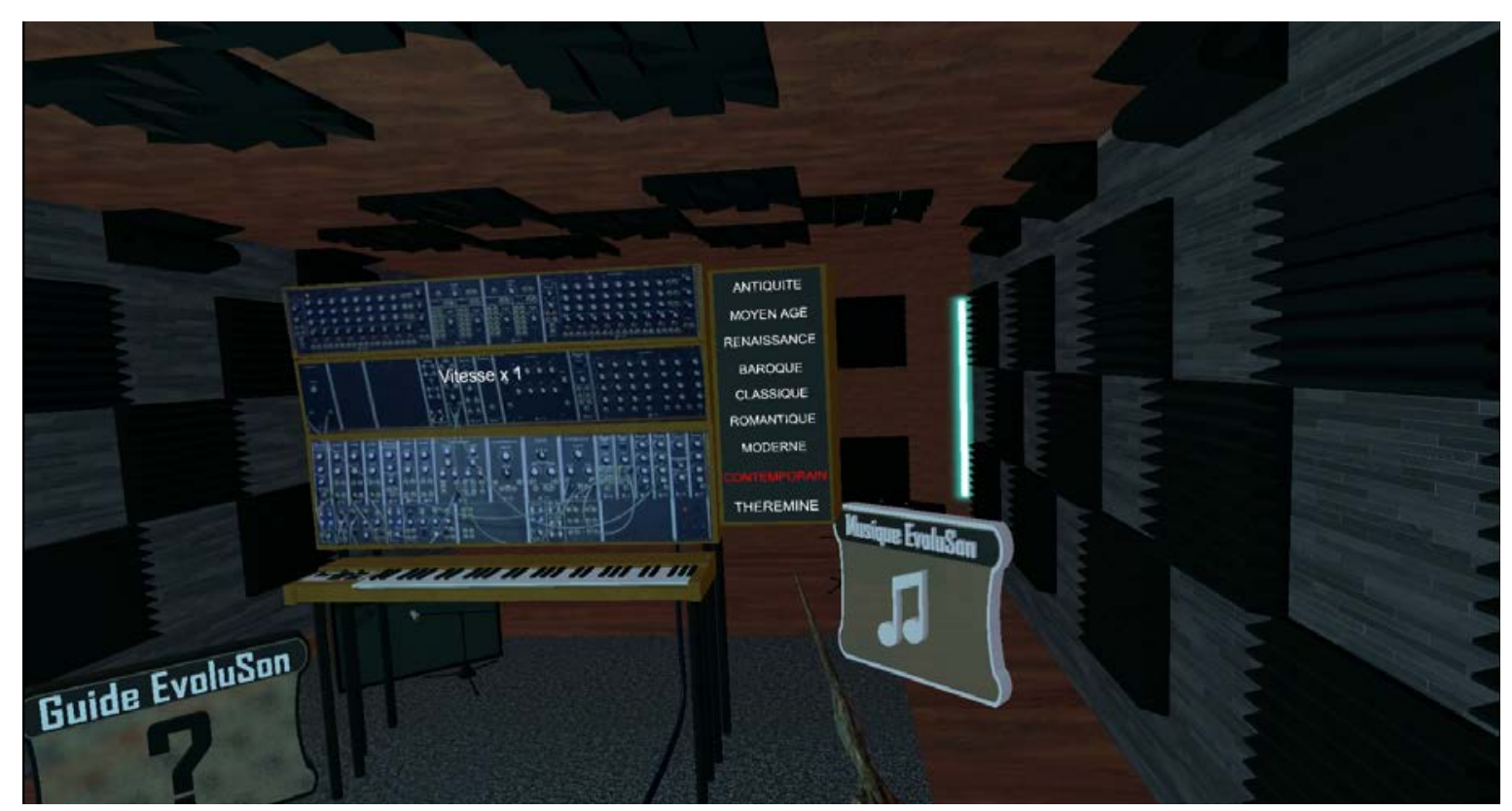

Figure 14. The moog console inside the live room

\subsection{Musical representation}

As presented in section 3, the musical representation of the eight era is based on variations of the theme of "Art of the Fugue" of Bach, in order to obtain a global coherence of the environment and fit the composition rules of each era.

\subsubsection{Antique garden}

The first musical environment of the application illustrates the musical Antiquity. The music appears as a background in the first stage of the project, in which the user discovers the interactive process of the virtual environment. The music has been sampled and is played in a loop. One of the 
main problems raised by this period is related to the timbre of the instruments used. Indeed, a big part of the instruments of this period did not survive through the ages, as well as the musical techniques. As it seemed irrelevant to compose a short piece that matches the stylistic features of this music, it has been decided to develop a sound environment based on acoustic instruments that are not directly related to Western music and its evolution but which represent relatively indistinguished timbre categories. One can ear two types of sounds. The first one comes from a Chinese bamboo flute and the other one aims to produce a particular percussive sound. The latter is produced from a few recorded sound clips of a classical guitar that are stretched to be longer which lower frequency, then transformed with a reverberation module.

\subsubsection{Middle Ages forge and Renaissance hall}

The musical practices of the Middle Ages and the Renaissance are pretty well documented by iconographical references. Many representations and paintings of instruments or groups of instruments are available. The appearance of musical and theatrical treatises, a first for this period, allowed us to precisely rewrite the chosen theme according to the aesthetic features that applied. As the musical rules that applied in those two historical periods are substantially the same, we decided to illustrate two different composition patterns. In the Middle Ages' room, the music is strictly instrumental and uses common instruments: one recorder, one harp, two lutes, a tambourine and a drum. The interactive possibilities of this room are not connected to the music because the visitor stands in a forge. Moreover, the sound of the music appears to come from the outside of the room and simulates the fact that this particular kind of practice is directly related to the public places as markets and streets. The piece is written as a rondeau, a musical form based on the alternation between verses and chorus, which was one of the most common song pattern due to its easy memorization.

Then the visit of the Renaissance hall is accompanied with vocal music, composed according to the rules of the $16^{\text {th }}$ century's counterpoint with references to Palestrina. To underline the differences of the practices between Renaissance and Baroque eras, we decided to write this piece for three voices, because the instrumental music was not yet independent and considered to be "serious". The interactions offered to the visitor in this room are linked for the first time to the music: when the size of the room gets increased, the spatialization of the synthesized voices and the quality of the reverberation change.

\subsubsection{Baroque chamber}

The main inspiration for the Baroque (1600-1750) period was the Dance Suite, particularly in Handel's style. The form of this piece is taken from the "bourrée". It alternates between strings, winds and tutti. The original subject has been upsized, and the notes are played mostly on a steady rhythm (Fig. 14).

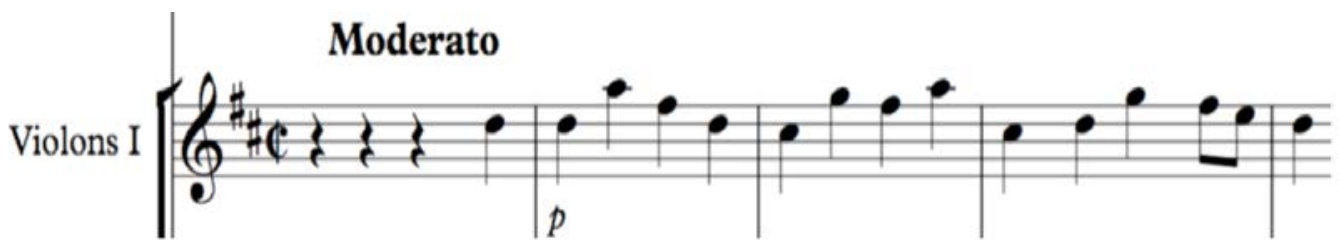

Figure 15: Baroque arrangement of the musical theme 
For this period, the interaction pattern is based on a balanced control between instruments. To increase this interaction, the work is based on a chamber orchestra placed around the room. Like Haendel's bourrée in his Water music, the composition alternates between 2 violins, 1 viola, 1 cello, 2 oboes and 1 bassoon. The choice of these instruments can surprise, because it does not correspond to the real instrumentarium of the Baroque era. However, the various sound banks available for this project didn't contain records of ancient instruments, and we had to choose modern instruments that fit the closest to the timbre of the period. Finally, because all the attention of the spectator in this room is dedicated to the instruments and the music, this stage portrays what can be considered as a new composition pattern of music. Indeed, this era marked in some ways the premises of the well-known live concert situation that will be developed in the next room.

At this time of the music history, the timbre is considered as a way to differentiate the parts of the polyphony, but it is not yet an expressive function in the composition. From this perspective, the placement of the instruments is not fixed, it mainly depends on the place in which the music is played. The interaction in the Baroque chamber has been designed in this way. The visitor can displace the different timbres he hears independently by moving the instruments in the visual simulation. He can also mute the instruments of his choice and readjusts the polyphony as he wishes.

\subsubsection{Classical room}

In the classical period, the piano became one of the most important instrument in the European musical landscape, and new genres of music appeared, dedicated to this instrument only. Lots of testimonies of this time show that usually the audience did not observe an almost religious silence, but stood near the stage and asked the musician to repeat a passage. This way of listening music is the starting point of the interaction implemented in this section. Besides, in our project, the music is conceived in order to create a brillante and con brio aspect that can be find in last movements of Haydn's sonatas. To these ends, the subject of Bach has been transposed in D major and the first two original bars have been extended (Fig. 15).

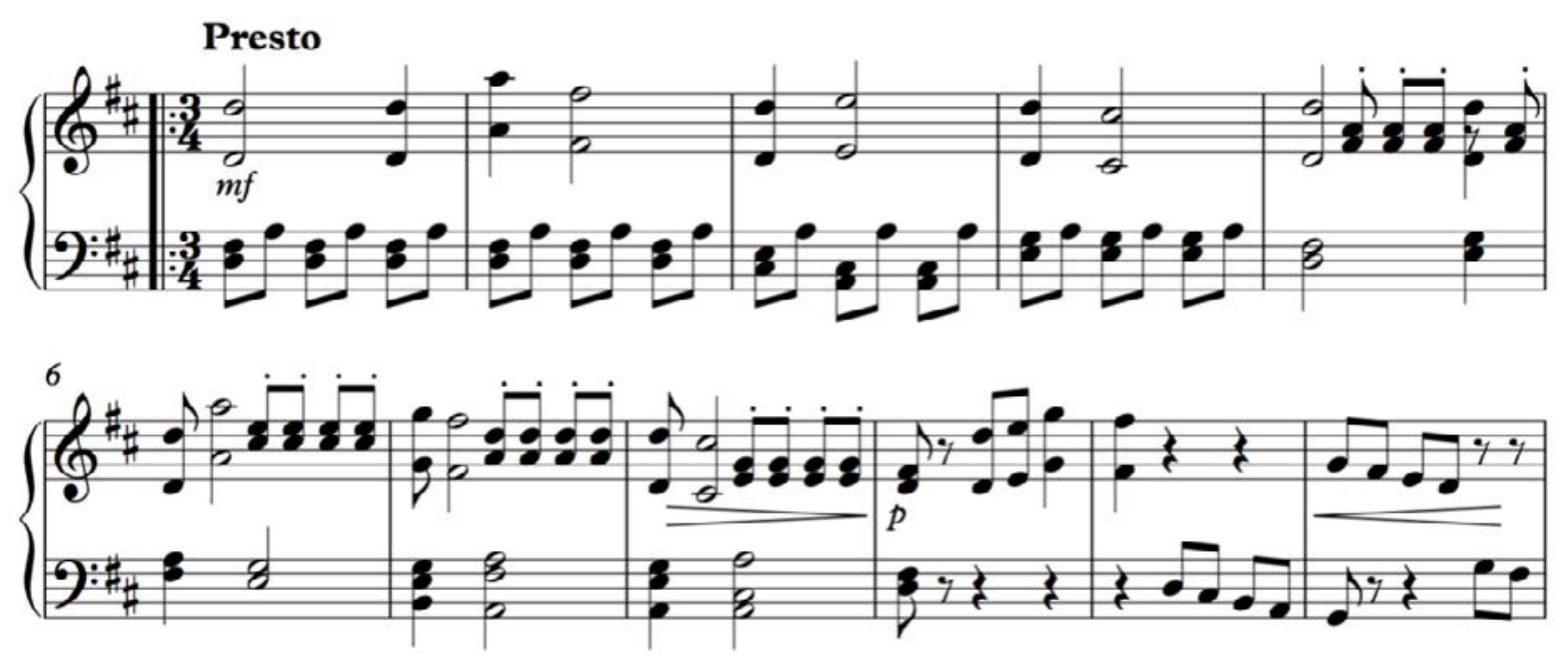

Figure 16: classical version of the main theme

This piece is written according to the ternary form that is the most important musical form of this period. A presentation, followed by a development and eventually a recapitulation (summary) is heard. 


\subsubsection{Romantic room}

For the romantic composition, in order to correlate the music and the representation of the period, it has been decided to create a waltz that is only related to Bach's theme by its tone.

As the room invites the spectator to wander on the stage, as if he becomes Baudelaire's flâneur, a secret passage has been implemented and leads to the Klosterfriedhof im Schnee, painted by Caspar David Friedrich in 1818. The spectator can dive into the painting to wander directly in a romantic landscape. Indeed, the wanderer's figure is essential in the aesthetic of this century, Schubert's Winterreise being a striking example. The waltz becomes a funeral march: the tonality turns to a minor scale, the rhythm changes to make the music more solemn. Moreover, it evokes the particular relation that composers have established with pictorial arts during the $19^{\text {th }}$ century, as we can observe in Modest Mussorgsky's work entitled Pictures at an Exhibition, based on Viktor Hartmann's drawings and watercolours. In this context, the entire stage represents the romantic imagery because it illustrate the loss of reason in favour of a creative wandering of the mind, as tormented and dark than magnificent and bright. That said, the nature of this interactive module does not directly concern the music, but the latter is a consequence of a visual interaction.

\subsubsection{Modern and contemporary rooms}

Finally, the music from the $20^{\text {th }}$ century was more difficult to deal with, due to the multiplicity of styles and musical systems used during this period. Furthermore, the century can be split in two major periods, hence rooms: the Modern one, which defines the first half of the century, and the Contemporary one, which begins after the second World War and continues in the beginning of the $21^{\text {st }}$ century.

To illustrate the Modern music, it has been decided to rewrite the theme accordingly to the dodecaphonic system, created by Arnold Schoenberg. One of the most important rules of this system is that a note can't be exposed before all the other notes has been played. You can hear the original theme on beat 1 and 4 of the measure 1 , on the beat 3 of the measure 2, on the beat 2 of the measure 3 and finally on the beat 1 and 4 of the measure 4 and so on (Fig. 16). The idea of stepwise motion close to the idea of elementary counterpoint has been preserved (Salzer \& Schachter, 1989). In this point of view, the series is a combination of two melodic lines, one based on the former subject and another one based on the harmonic series.

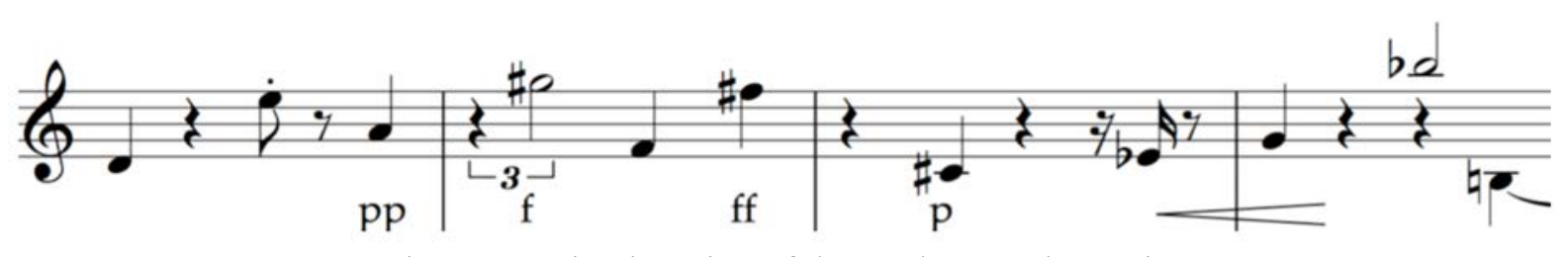

Figure 17: First iteration of the modern work's series

In this perspective, the interaction modules implemented in this part allow the spectator to manipulate the music by applying the three main transformation modes of the series: the diminution or augmentation of the rhythmical values - so it appears to be played faster or slower - the transposition - represented by a low-pass and a high-pass filter - and the retrograde and/or the inversion of the series - simulated by a reverse-play lever. The interactions are performed through two industrial machines as described in the section Interactions below. 
The Contemporary room represents one of the most important revolution in music history: for the first time, the music can now be played in a studio or, in other words, the experience of music has been isolated from its performance due to the massive democratisation of the recording technologies. This final room contains a simulation of a ThereminVox, which is one of the first electronic instrument that has been invented in 1928, which sound is iconic of the electronic timbre developed during the second half of the twentieth century. Thereby, it permitted the invention of a new kind of electronic instruments in which the interface between the musician and the instrument is dematerialized. To match with the most important invention of this period, it has been decided to create a musical part based on the capacity of manipulating the sound offered by new technologies. The material is made of samples of voices, synthetic sounds and rhythmic loops, inspired by some vocal and instrumental treatments of the sound in Fakear's song, Neptune.

Because this room ends the visit, it has also been decided that the user can have access to all the musical parts he heard during his journey. The various pieces of music constitute a sound bank that can be modified. Disposed on a synthesizer Moog, diverse controls are provided to "play" with the sound matter as detailed in the Interactions section below.

\subsection{Interactions}

The interactions with the environment are specific to each era.

In the Antiquity era, the user can break Antique vases, producing a breaking noise (Fig. 18).

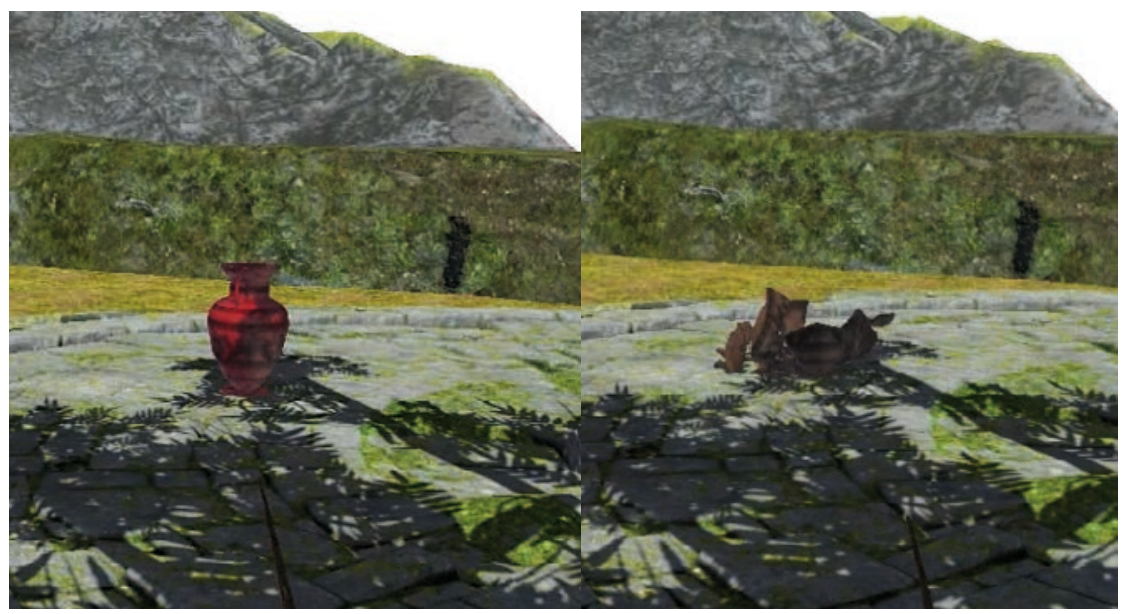

Figure 18. Interactions in the Antique garden

In the Medieval period, the user interacts with two characters, the blacksmith dwarf and the paladin who both speak when activated. A fight with the paladin is proposed to the user who must find a strong-enough sword to defeat him (Fig. 19). Three swords are hidden in the room, and when the visitor catches them, they replace the wooden stick hold by him, until he/she leaves the room. 


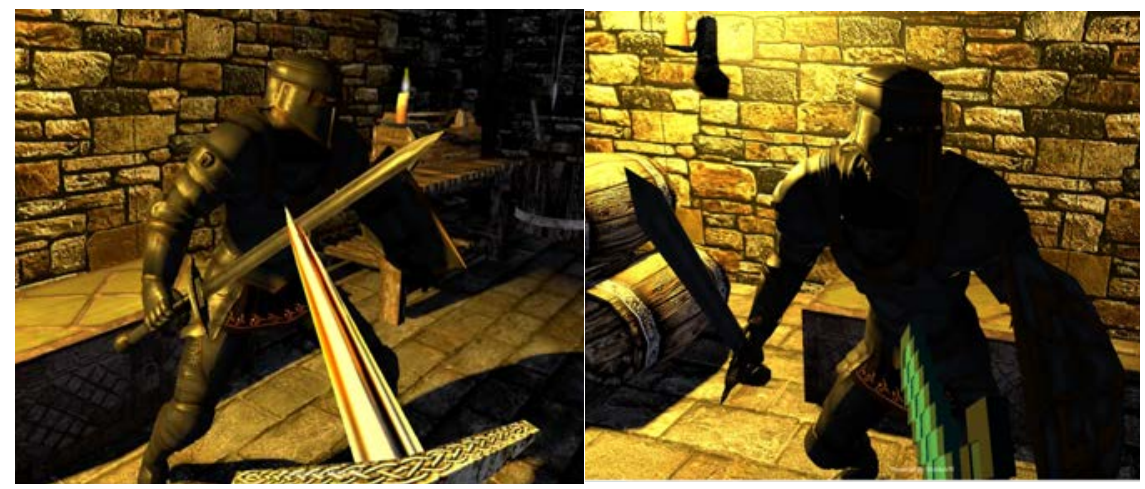

Figure 19. Interactions in the Medieval blacksmith

In the Renaissance era, the user can point and click on the back wall, provoking the two lateral walls to move either outward or inward (Fig. 20), which changes the dimensions of the room and the reverberation of the music in the room. He also can switch on and off a fire in the fireplace.

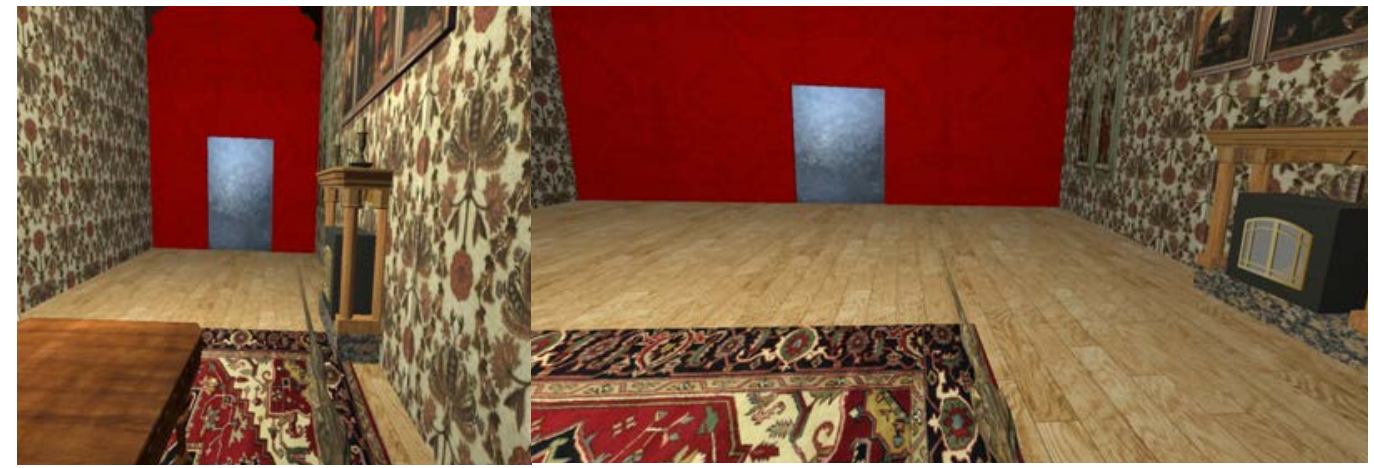

Figure 20. Interactions in the Renaissance room

In the Baroque era, the user can catch and move the seven instruments in the bedroom (Fig. 21). The music played by each instrument is co-located with the position of the instrument. Each instrument can also be switched on and off independently from other instruments.

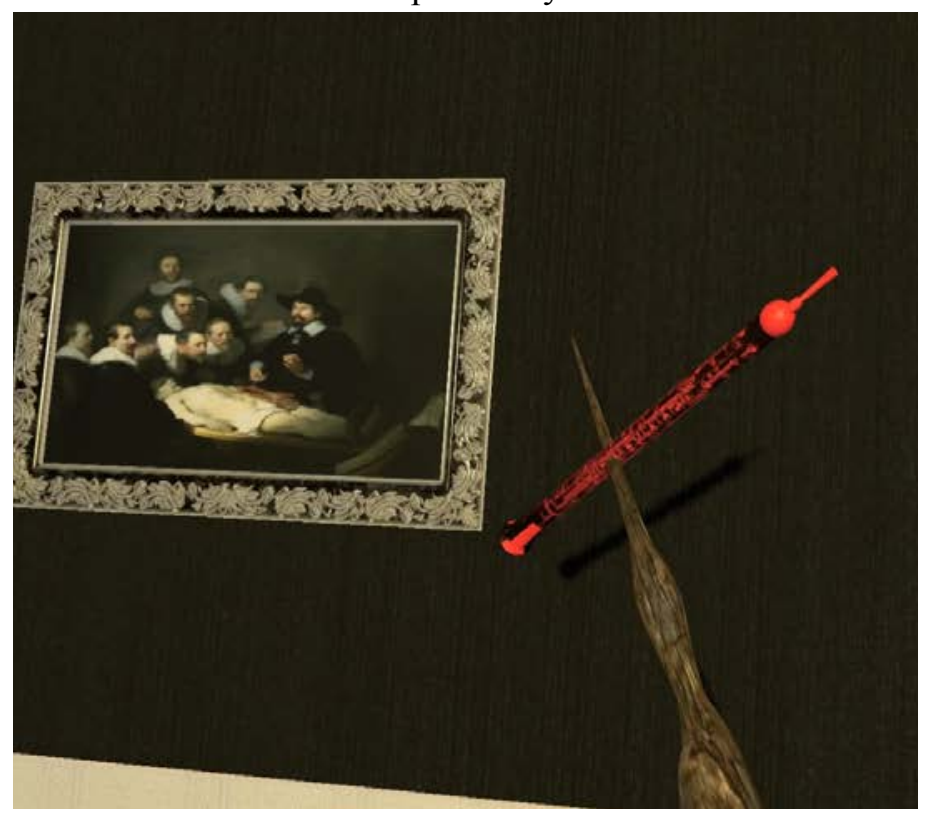

Figure 21. Interactions in the Baroque chamber 
In the Classical era, the music sheet on the piano is interactive: a cursor is following the music being played and can be moved by the user everywhere in the music sheet (Fig. 22). When the cursor is moved, the music follows at the new position.

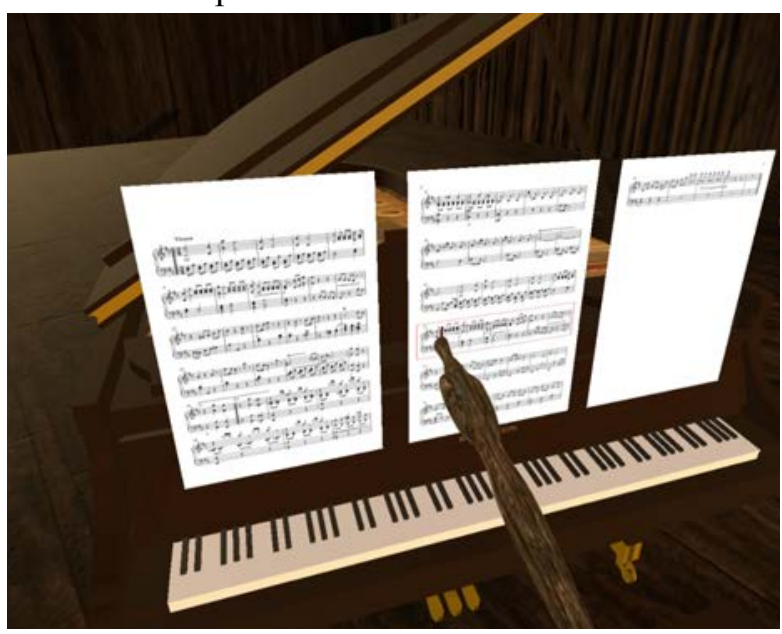

Figure 22. Interactions in the Classical theatre

In the Romantic era, the visitor is invited to find a secret room in the ballroom. When he/she succeeds to open and to enter in the secret room (Fig. 23), he/she can point and click on the Romantic painting on the wall. The visitor is then teleported inside a 3D reproduction of the painting, with a change on the Music that is described in the next section. He/She can navigate to the ruins of the monastery. A magic stone in the middle of the ruins allows the visitor to come back to the ballroom.

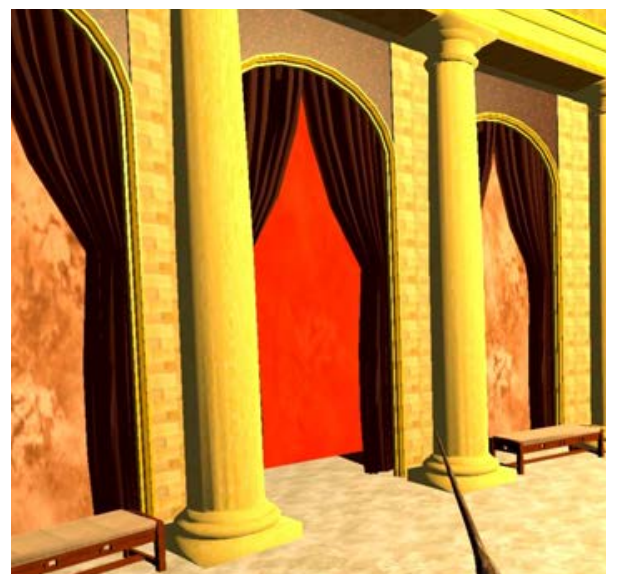

Figure 23. Interactions in the Romantic ballroom

In the Modern era, the visitor can control the music with the levers of two electrical machines. The machine on the left allows to launch and control speed of the music (Fig. 24, left). The machine on the right allows to apply some effects on the music: a reverse play, one high-pass and one low-pass filters, and one echo effect (Fig. 24, right). The gears turn according to the speed and direction of the music. 


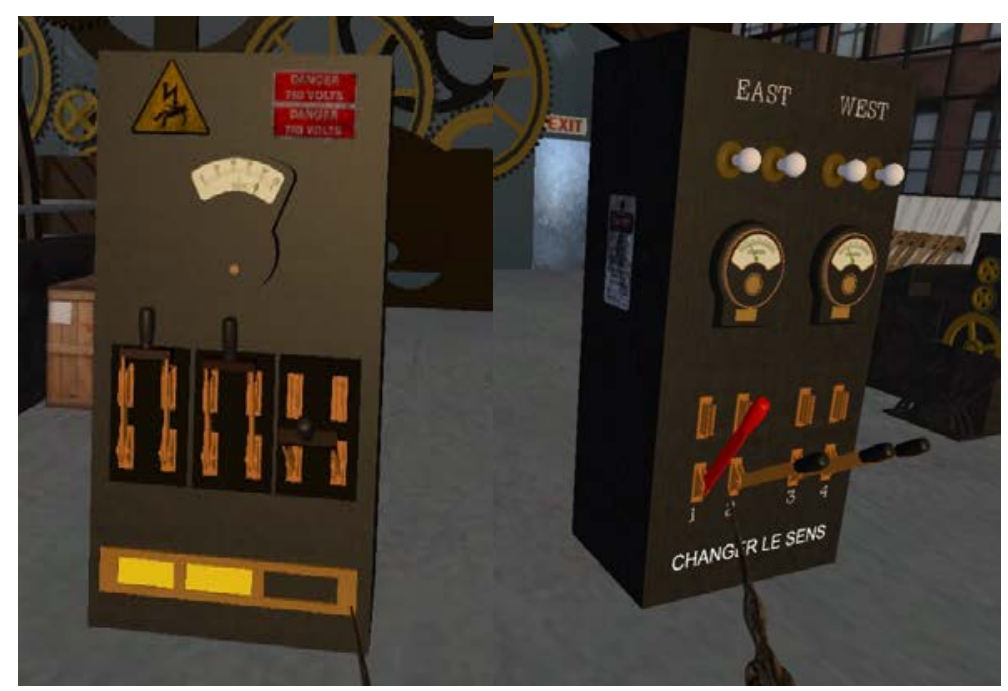

Figure 24. Interactions in the Modern factory

In the Contemporary era, the moog console proposes various effects that can be applied to all the musical compositions of EvoluSon: an echo with a configurable delay, high pass and low pass filters with configurable thresholds, a chorus filter to divide the tone, a distortion, and a configurable reading speed that reverses the music when its value is negative (Fig. 25). The visitor can also activate a Theremin and play a sound controlled by the positions of the wand as detailed in the technical section below.

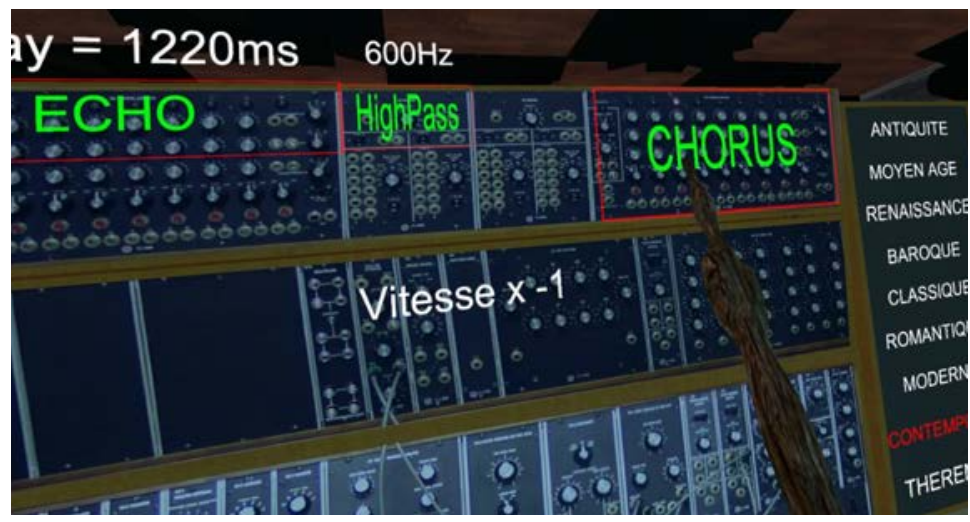

Figure 25. Interactions in the Contemporary studio

\subsection{Technical description}

Graphical elements and animations were designed with Autodesk 3DS Max. The interactive simulation was implemented with Unity 3D and MiddleVR. Unity 3D is a widespread cross-platform game creation system developed by Unity Technologies. It includes a game engine and an integrated development environment. MiddleVR is a generic immersive virtual reality plugin compatible with Unity. It handles interaction devices such as 3D trackers, stereoscopy, clustering with software and hardware scenelock and swaplock, and 3D interactions.

The musical pieces were designed and synthesized with Finale, Cubase and East-West Symphonic Orchestra, except the Antique piece that was recorded by its composer using traditional Chinese flutes.

The Theremin was implemented in a Max/MSP 6 patch. The synthetic sound is based on simple harmonic series. The communication between Unity3D and Max relies on the Open Sound Control (OSC) protocol, using the UnitOSC plugin on the Unity side. Unity can switch the patch 
output on and off following the user inputs in the application. When the Theremin is activated on the Moog console, data about the tracked wand, i.e. position and orientation (euler angles) are sent to Max. The Max patch consists in mapping some components of these data to effects on the initial harmonic series. The component of the orientation on the forward axis modifies the output volume, so that when the tracked wand is tilted on the left, the volume is decreased and when it is tilted to the right, it is increased. The tilt angle between $-90^{\circ}$ and $+90^{\circ}$ is mapped to the range $[0,1]$ providing a ratio that is multiplied to the maximum volume. The component of the position on the left/right axis is used to control the pitch of the sound, which gets scaled from its min and max values to the 250 $2000 \mathrm{~Hz}$ range and used to generate a sinusoidal wave with a $0.1 \mathrm{hz}$ additional modulation.

The resulting VR application was deployed on Oculus DK2 HMD with Razer Hydra device, on HTC Vive HMD, and on a large CAVE-like immersive facility, consisted of four glass screens, a front one, two sides and a ground with an overall dimension of $9.6 \mathrm{~m}$ wide, $3 \mathrm{~m}$ deep and $3 \mathrm{~m}$ high. Over 20 million pixels are displayed using a video projection system combining thirteen 3D HD Barco projectors. The tracking system is composed of 16 ART TRACK2 infrared cameras. Sound is spatially rendered using a 10.2 sound system.

\section{Discussion}

The EvoluSon project offers an innovative way to introduce the history of Western music. The immersive and interactive visual environment allows to include the presentation of the music in a context of interpretation which is impossible to transcribe with sound devices only. The technology itself is secondary; the project has been presented in different technological contexts, either in an immersive room or with HMDs.

The problems raised by the implementation of relevant interactions regarding the pedagogical ends of the project led us to design "magical" interaction metaphors that could not be used in the real world, like the walls moving upon request to change the acoustical properties of the Renaissance hall, the floating instruments in the Baroque bedroom, or the diving into the painting.

\subsection{Project implementation}

The joint work between artists and computer scientists was one of the motivations of the project between the two research laboratories. The course of the project makes it possible to make some interesting observations on its orientation. During the implementation of the project, we can note a particular approach between artists and computer scientists. The composition of the different musical parts follows a scientific methodology by carrying out a writing exercise based on the analysis of the main musical rules and structures used in the different epochs. Therefore, the music offers an overall representation of the evolution between the various styles that is simplified according to the pedagogic meaning of the project, but remains accurate.

In the work of implementation, computer scientists had to imagine an interactive universe that emphasizes music and introduces a representation of its context of interpretation. There has been a great deal of creativity in the graphic realization of the different epochs, which incorporates numerous references to other artistic domains, and also in the realization of "magic" interactions. The realization of the project was made possible by a strong interaction between the two communities.

During its design and development, the EvoluSon project had to face some difficulties, challenges or traps to avoid. 
First, the will to highlight intangible cultural contents like music and composition made it possible to overcome the constraints of visual realism. A different approach could have been to propose a completely abstract visual space linked to a representation of the sound space as it is often the case in music visualizers. The theme of the project, the history of Western music, gave more meaning to a visual representation of historical scenes. This visual representation of music related to different epochs gives the visitor a direct understanding of the musical context.

Conversely, there was a risk of perceiving music as an element of ambience in a visual experience, as in [Froschauer et al. 2010] where music and sounds are designed to remain "discreet, not to distract the player from the learning content". On the contrary, in EvoluSon, the music must occupy a central position. In order to avoid this pitfall, the visitor is brought progressively to interact with the music until the final room where he has a set of tools to create a personal sound space from the different musical pieces of the temporal journey and with the Theremin.

Another specificity of the EvoluSon project that reinforces the position of music in the VR experience is the fact that the compositions are based on a formal classical construction, with a rich set of inspirations. Each musical composition was inspired from innovative academic music with a lot of personality with respect to the corresponding eras. The frequent changes of style and instrumentarium and the original compositions allow to maintain the user attention to the music.

An important aspect of the project, which has generated many debates, drafts and tests, is the representation of the time travel, with the representation of the changes of epochs while preserving a quality of the user experience. The temptation was great to propose original navigations with intense special effects, especially to characterize the changes of epochs. The sound accompaniment of the period changes was also a question that has arisen. Working on a recurring musical theme has finally oriented the temporal journey towards a path in a linear space, with an overlap of the music during the period changes and a very slight transition materialized by doors that evaporate gradually while the user comes closer. This choice made it possible to preserve music as the centre of the experience and the main thread of the journey.

\subsection{Project evaluation}

The first public exhibition of the project was in the context of the "science and music day", in October 2016, organised by the computer science research laboratory. During the day, one hundred visitors experienced the project in the large immersive facility (Fig. 19). Each visitor experienced an average of 3 rooms (Mean $(M)=2.9$; Standard Deviation $(S D)=2.0$ ) in EvoluSon during 4 minutes. A questionnaire was proposed to the visitors in order to evaluate their experience. 55 visitors filled the questionnaire, $54.8 \%$ of women, and $45.1 \%$ of men. On average, they were 34 years old $(\mathrm{M}=33.97$; $\mathrm{SD}=15.07)$. Among the visitors, 13 were musicians, 15 declared to regularly play video games (including 6 musicians), and 7 had already experienced VR devices. 


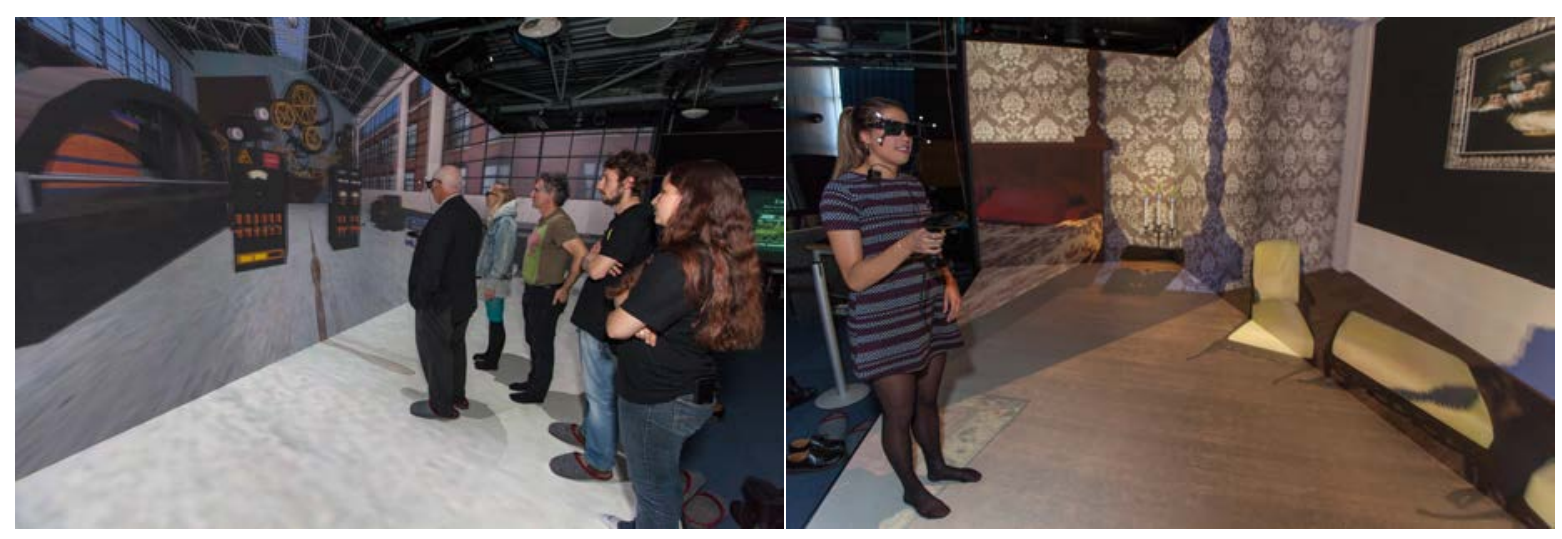

Figure 26. Presentation of EvoluSon during the Science and Music Day

The questions related to the experience intensity in virtual reality, music and learning, and an evaluation of the virtual reality environment (navigation, interaction, 3D perception, sound perception). A five-levels scale rate was proposed to answer the different questions from "1 very weak" to " 5 very strong". The results for the experience intensity are ranked as strong for virtual reality $(\mathrm{M}=4.2, \mathrm{SD}=0.7)$, and between standard and strong for music and learning (resp. $\mathrm{M}=3.2$, $\mathrm{SD}=0.9$, and $\mathrm{M}=3.6, \mathrm{SD}=1.1$ ). We can conclude that the experience was positive, with stronger experience intensity in VR. This is very probably related to the impressive immersive facility used during this event. Learning and music experiences are more difficult to evaluate, as the visitors did not access all the rooms. Learning and pedagogical impact of EvoluSon were not evaluated during the public event. Such evaluation should be interested but requires a specific protocol to compare what is learnt by visitors of EvoluSon with respect to what is learnt in a classical scholar presentation of the history of Western music. Navigation ease, interaction and music perception in the VR environment were evaluated between normal and strong (resp. $\mathrm{M}=3.6, \mathrm{SD}=0.9, \mathrm{M}=3.7, \mathrm{SD}=0.9$ and $\mathrm{M}=3.6$, $\mathrm{SD}=1.1)$, and $3 \mathrm{D}$ perception was evaluated as between strong and very strong $(\mathrm{M}=4.3, \mathrm{SD}=0.8)$. The overall evaluation of the VR environment is positive while we can note one drawback in the configuration proposed to the visitors: the sound rendering through external speakers.

During the public event, the audio broadcasting system was made of 10 speakers and 2 loud speakers, which resulted, combined with the hubbub of the visitors and the noise of ventilation, in a degraded but shared musical experience. An alternative solution to enhance the musical experience would have been to use an audio headset. This solution has the advantage to be compatible with a binaural transformation of the sound to provide a better spatialization as presented in (Grani et al. 2014).

A last question in the evaluation was related to the adequacy between music and visual environment: "Do you consider that the music is in agreement with the images of the 3D environment?" The possible answers were "yes", "no" or "without opinion", and 92,7\% of the visitors answered positively to the question (51 "yes", 2 "no" and 2 "without opinion"). This result positively validates the goal of EvoluSon to propose a musical and visual journey in the history of Western music.

\section{Conclusion}

The EvoluSon project associated computer scientist and students, and researcher and students in art and music, to propose an immersive and interactive journey in the history of Western music. The resulting artwork was first presented in a large immersive facility during a public event on science and music, where the visitors, who appreciated the immersive experience, and the interactions with both 
visual and musical environments, positively evaluated it. It was subsequently presented to another public event dedicated to art and science, using an HMD-based installation, and to various scholar events for high school and college students, either on HMDs or in the large immersive facility.

The EvoluSon project contributes to enrich the approaches in culture and heritage applications, with the design and implementation of an interactive exhibit for a public event that proposes a time travel in the history of Western music.

The result of the project illustrates how virtual reality can be used to create and communicate an intangible cultural content and its evolution across the time. This opens interesting perspectives for the creation of innovative interactive exhibits in public spaces and museums that propose at the same time an artistic, cultural and digital experience. In order to investigate this perspective, the technology and concepts associated to VR must integrate art and culture and their relationship with users. In particular, interactions need to be carefully designed to support the cultural content and to favour a commitment of the user. In EvoluSon, the interactions were designed to create a growing relationship between the visitor and the music. Immersive VR reinforces this relationship by putting the visitor in a meaningful context. It should be interesting in a future work to design an evaluation of the pedagogical impact of EvoluSon in a scholar context in order more precisely quantify the interest of such approach. The coherency in the design of the visual content, the musical compositions, and the interactions, with respect to the different eras of the history of Western music, are strong bases to promote EvoluSon as a VR application useful for education in culture and heritage.

Music is at the heart of EvoluSon. The original compositions, mostly based on academic classical music, procure a rich artistic dimension to the resulting immersive VR application. Other fields of music, especially popular music, could also be explored with this kind of approach. Improved interactions related to intangible culture like dancing should also benefit from and enrich it. The magical dimension made possible by virtual reality solicits the visitor's emotion and imagination and unveils inspiring perspectives.

\section{References}

Berthaut, F., Marshall, M., Subramanian, S., \& Hachet, M. (2013, May). Rouages: Revealing the mechanisms of digital musical instruments to the audience. In New Interfaces for Musical Expression (pp. 6-pages).

Berthaut, F., Zappi, V., \& Mazzanti, D. (2014). Scenography of immersive virtual musical instruments. In VR Workshop: Sonic Interaction in Virtual Environments (SIVE), 2014 IEEE (pp. 1924). IEEE.

Bishop, M.J. (2014). Thinking more dynamically about using sound to enhance learning from instructional technologies. In K. Collins, H. Tessler, \& B. Kapralos (Eds.), The Oxford Handbook of Interactive Audio. New York: Oxford University Press.

Blesser, B., \& Salter, L. R. (2009). Spaces speak, are you listening?: experiencing aural architecture. MIT press.

Bowman, D., Kruijff, E., LaViola Jr, J. J., \& Poupyrev, I. (2004). 3D User Interfaces: Theory and Practice, CourseSmart eTextbook. Addison-Wesley. 
Bowman, D. A., Koller, D., \& Hodges, L. F. (1997, March). Travel in immersive virtual environments: An evaluation of viewpoint motion control techniques. In Virtual Reality Annual International Symposium, 1997., IEEE 1997 (pp. 45-52). IEEE.

Carrozzino, M., \& Bergamasco, M. (2010). Beyond virtual museums: Experiencing immersive virtual reality in real museums. Journal of Cultural Heritage, 11(4), 452-458.

Castro, B. M., Alonso, L. B. N., Ferneda, E., da Cunha, M. B., Cruz, F. W., \& Márcio da Costa, P. B. (2006). BDB-MUS: a project for the preservation of Brazilian musical heritage. In ISMIR, pp. 337339.

Champion, Erik. (2011). Playing With The Past. HCI series, Springer-Verlag UK.

Champion, E. (2015). The cultural and pedagogical issues of new media and the humanities. In $\mathrm{Yu}$ Ping, Li Fengliang et al. (eds.), Annual Report of Culture and Technology Innovative Development, Social Sciences Academic Press, Shenzhen China. ISBN: 978-7-5097-8222-4.

Charles Baudelaire, Le Peintre de la vie moderne, Paris, Fayard, collection « la petite collection », 2010

Dale, E. (1969). Audiovisual methods in teaching. (3rd Edition), Holt, Rinehart, and Winston, Inc. New York.

Die Kunst der Fuge: Cembalo (Klavier) = The art of fugue; cembalo (Piano) BWV 1080, München; [Milwaukee, Wis., Henle ; Distributed in the USA by Hal Leonard Corp., 2012.

Froschauer, J., Seidel, I., Gärtner, M., Berger, H., \& Merkl, D. (2010). Design and evaluation of a serious game for immersive cultural training. In Virtual Systems and Multimedia (VSMM), 2010 16th International Conference on (pp. 253-260). IEEE.

Grani, F., Argelaguet, F., Gouranton, V., Badawi, M., Gaugne, R., Serafin, S., \& Lecuyer, A. (2014, March). Design and evaluation of Binaural auditory rendering for CAVEs. In Virtual Reality (VR), 2014 iEEE (pp. 73-74). IEEE.

Jørgensen, M. H., Knudsen, A. S., Wilmot, T. M., Lund, K. D., Serafin, S., \& Purwins, H. (2015). A Mobile Music Museum Experience for Children. In E. Berdahl (Ed.), Proceedings of the International Conference on New Interfaces for Musical Expression (NIME 2015). (pp. 36-37). Louisiana State University.

Leonard, J., Cadoz, C., Castagné, N., Florens, J. L., \& Luciani, A. (2013). A Virtual Reality Platform for Musical Creation: GENESIS-RT. In International Symposium on Computer Music Modeling and Retrieval (pp. 346-371). Springer International Publishing.

Nakra, T. M., Ivanov, Y., Smaragdis, P., \& Ault, C. (2009). The UBS Virtual Maestro: an Interactive Conducting System. In NIME, pp. 250-255.

Nordahl, R., \& Nilsson, N. C. (2014). The Sound of Being There: Presence and Interactive Audio in Immersive Virtual Reality. In The Oxford Handbook of Interactive Audio (Chapter 13). Oxford University Press. (Oxford Handbooks). DOI: 10.1093/oxfordhb/9780199797226.013.013 
Osberg, K.M., (1995) Virtual reality and education: where imagination and experience meet, $V R$ in the Schools 1 (2) 1-3.

Papagiannakis, G., Foni, A., \& Magnenat-Thalmann, N. (2003). Real-Time recreated ceremonies in VR restituted cultural heritage sites. In CIPA XIXth International Symposium (Vol. 30).

Pressing, J. (1997). Some perspectives on performed sound and music in virtual environments. Presence: Teleoperators and Virtual Environments, 6(4), 482-503.

Salzer, F. \& Schachter, C., (1989), Counterpoint in composition. New York, Columbia University Press.

Serafin, S., Erkut, C., Kojs, J., Nilsson, N. C., \& Nordahl, R. (2016). Virtual Reality Musical Instruments: State of the Art, Design Principles, and Future Directions. Computer Music Journal. $40: 3$, pp. $22-40$

Simon, L. S., Nouviale, F., Gaugne, R., \& Gouranton, V. (2014). Sonic interaction with a virtual orchestra of factory machinery. In VR Workshop: Sonic Interaction in Virtual Environments (SIVE), 2014 IEEE (pp. 7-12). IEEE.

Sylaiou, S., Mania, K., Karoulis, A., \& White, M., (2010), Exploring the relationship between presence and enjoyment in a virtual museum, International journal of human-computer studies, 68 (5), 243-253.

Valbom, L., \& Marcos, A. (2007). An immersive musical instrument prototype. IEEE computer graphics and applications, 27(4), pp. 14-18. 